Portland State University

PDXScholar

Dissertations and Theses

Dissertations and Theses

1980

Computer Aided Optimal Design of Helical Gears

S. N. Muthukrishnan

Portland State University

Follow this and additional works at: https://pdxscholar.library.pdx.edu/open_access_etds

Part of the Mechanical Engineering Commons

Let us know how access to this document benefits you.

Recommended Citation

Muthukrishnan, S. N., "Computer Aided Optimal Design of Helical Gears" (1980). Dissertations and Theses. Paper 4192.

https://doi.org/10.15760/etd.6075

This Thesis is brought to you for free and open access. It has been accepted for inclusion in Dissertations and Theses by an authorized administrator of PDXScholar. Please contact us if we can make this document more accessible: pdxscholar@pdx.edu. 
AN ABSTRACT OF THE THESIS OF $S$. N. Muthukrishnan for the Master of Science in Mechanical Engineering presented December $21,1990$.

Title: Computer Aided Optimal Design of Helical Gears.

APPROVED BY THE MEMBERS OF THE THESIS COMMITTEE:

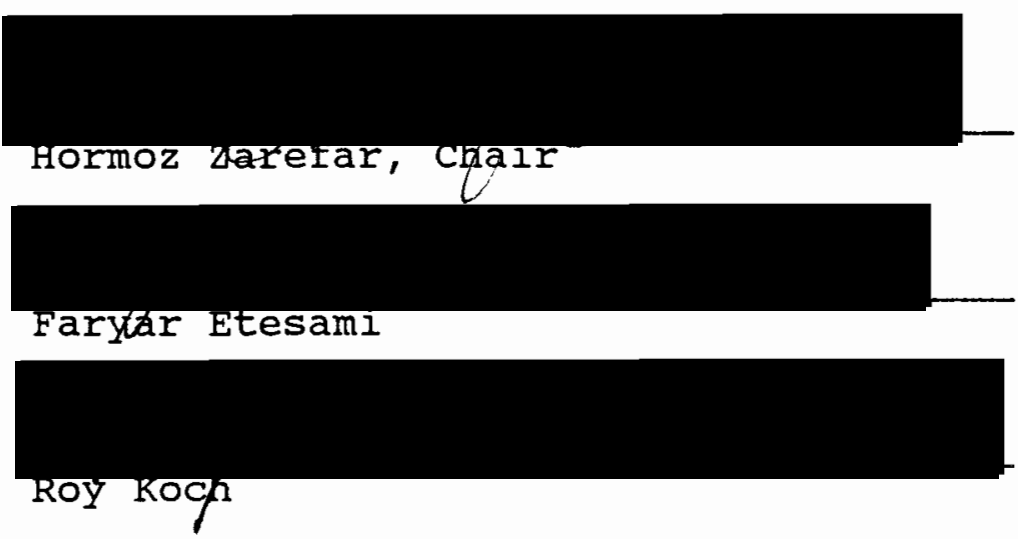

A random search method for optimum design of a pair of helical gears has been developed. The sequence of optimization consists of two principal components. The first is the selection phase, where the output is the starting solution for the design variables - module, facewidth, helix angle and number of teeth on the pinion. The input for the selection phase includes the application environment, approximate center distance, minimum helix angle, desired values of gear ratio, pinion speed and the power to be transmitted. The limits on each of the design variables and the constraints are imposed interactively during the first phase. A standard tooth form is 
assumed for the design. Standards published by the American Gear Manufacturers Association are employed for the design process.

The second phase consists of the implementation of the optimization procedure to find the minimum weight. The method employs a random number as the search direction with the step size being altered based on the value of the constraints. A number of random directions are generated and a minimum in each of those directions are determined to form a set of feasible solutions. The optimum solution is then determined from the set of feasible solution. Graphs are presented during optimization to create a user interactive environment. The program generates a complete set of manufacturing data for the designed gear. 


\title{
COMPUTER AIDED OPTIMAL DESIGN OF HELICAL GEARS
}

\section{by}

S. N. MUTHUKRISHNAN

A thesis submitted in partial fulfillment of the requirements for the degree of

\author{
MASTER OF SCIENCE \\ in \\ MECHANICAL ENGINEERING
}

Portland state University

1991 
TO THE OFFICE OF GRADUATE STUDIES:

The members of the committee approve the thesis of

S. N. Muthukrishnan presented December 21, 1990.

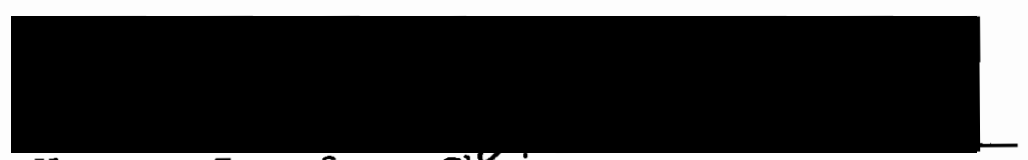

Hormoz Zarefar, Chair

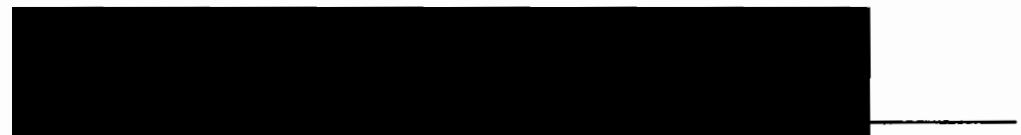

Faryar etesami

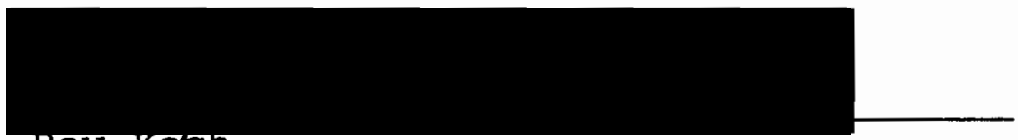

Roy kqen

APPROVED :

Gralg A. \$polek, Chalr, Department of Mechanical Engineering

C. William Savery, Interim vice Provost for Graduate studies and Research 
This work is dedicated to the doyens of Engineering, who by virtue of their sincere and meticulous effort

have helped me reap the fruits of their hardwork. 


\section{ACKNOWLEDGEMENTS}

I express my sincere and profound gratitude to all the members of my Graduate thesis committee for their guidance and support that has helped me in the successful completion of the project. It is difficult for me to find words of thankfulness and sincere appreciation for all the support and encouragement I received throughout my Master's program from my advisor, friend, philosopher and guide, Dr. Hormoz Zarefar. I thank Dr. Faryar Etesami for his little pieces of many advice. I record my gratitude for Dr. Graig spolek for the encouragement, personal attention and support he has provided me. My genuine appreciation to the secretaries of the Mechanical Engineering department - Debbie and Maxine for their instant attention and willingness to help, even if it were to be out of their way. My dear friends Rajkumar (K.D), Jerry and Selva, all of them receive my equal appreciation for their enduring attitude and patience they have shown.

It would make all my effort fruitless if I were not to thank the members of my family - my father, mother and brother for the keenness they have shown in my studies and well-being. Last, but not the least, I thank the Almighty for the guidance I received throughout my life. My thanks to all those who have made my stay in Portland a lively and memorable one. 
CONTENTS

ACKNOWLEDGEMENTS . . . . . . . . . . . . . . . . iv

LIST OF TABLES . . . . . . . . . . . . . . . . . vii

IIST OF FIGURES . . . . . . . . . . . . . . . . . viii

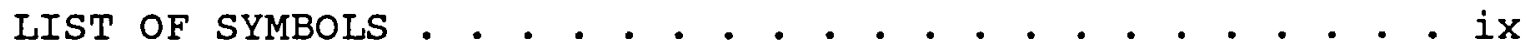

CHAPTER

PAGE

I BACKGROUND . . . . . . . . . . . . . . . . . . 1

1.1 Optimization . . . . . . . . . . . . . . . 1

1.2 Optimization in Mechanical Design . . . . . . 5

1.3 Computers in Optimal Design . . . . . . . . 6

1.4 Definition of Problem for optimization . . . . 7

1.5 Optimal Design of Gears . . . . . . . . . . 9

1.6 Objective of This Project. . . . . . . . . 10

II RANDOM SEARCH ALGORITHM FOR OPTIMIZATION . . . . . 12

2.1 Numerical Methods in Optimization . . . . . . 12

Optimization in Mechanical Engineering

Design: An Example . . . . . . . . 14

2.2 Terminologies and Notation . . . . . . . 16

2.3 Random Search Methods . . . . . . . . 16

Adaptive Random Search . . . . . . . . 17

Adaptive Step Size Random Search . . . . 18

Combinatorial Heuristic Method . . . . 18

2.4 The Modified Adaptive Step Size Random Search . 19

The Approach . . . . . . . . . . . . 19

The Algorithm . . . . . . . . . . . 20 
Mathematical Representation of The Random Search . . . . . . . . . . . 23 Graphical Interface . . . . . . . 25

III APPLICATION OF RANDOM SEARCH TO OPTIMAL DESIGN OF HELICAL GEARS . . . . . . . . . . . 28

3.1 Helical Gear Optimization . . . . . . . . 31

3.2 Problem of Helical Gear Design . . . . . . 32 objective . . . . . . . . . . . 32 Constraints . . . . . . . . . . . . 33 Design Variables . . . . . . . . . 34

3.3 Design Example . . . . . . . . . . . 34

3.4 Result and Discussion . . . . . . . . . 35

IV CONCLUSION . . . . . . . . . . . . . . . 4 4

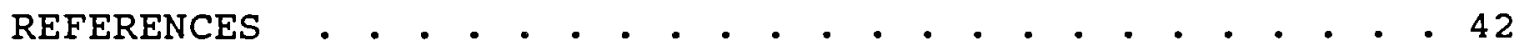
APPENDICES

A HELICAL GEAR DESIGN PROCEDURE . . . . . . . . . 45

B RANDOM SEARCH METHOD AS A USER CALLABLE PROGRAM • . 51 C TABLES USED IN HELICAL GEAR DESIGN . • . . . • . 55 


\section{LIST OF TABLES}

TABLE

PAGE

Discrete values represented continuously . • . 6 Solution for the non-linear minimization problem • . . . . . . . . . . . . . . . . 29

III Solution for the three bar truss problem . . . 31 IV Solution for the helical gear problem . • • • 37 V Gear design details for manufacturing . . . . . 40 VI A broad classification of applications • • • . 56 VII Application and suggested quality numbers for spur, helical, herringbone, bevel and hypoid gears, racks and worm gearing . . . . . . . 57

VIII Minimum number of teeth required on pinion for different helix and pressure angles . . . . . 62

IX Recommended hardness values for steel gears for different ranges of number of pinion teeth • . 62 $\mathrm{X}$ Table of $\mathrm{K}$-factor values for different applications . . . . . . . . . . . . 63

XI Allowable contact stress values for different steel gears . . . . . . . . . . . . . 64

XII Allowable bending stress values for different steel gears . . . . . . . . . . . . . 65

XIII Application factors $k_{a}$ and $c_{a}$ for various applications . . . . . . . . . . 66 


\section{LIST OF FIGURES}

FIGURE

PAGE

1.

Optimum design process . . . . . . . . . . 3

2 .

Conventional design process . . . . . . . . 3

3.

Design space . . . . . . . . . . . . . . . . . 9

4 .

A circular ring in tension . . . . . . . . 15

5. Flowchart for the modified adaptive step size random search technique . . . . . . . . . 22

6. Graphs presented to user as a part of interactive optimization . . . . . . . . . 26

7. Three bar truss problem . . . . . . . . . . 29

8. Graphs showing minimum of each design variable with every random number . . . . . 38

9. Graphs showing behaviour of design variables for a given random number . . . . . . . . 39 


\section{LIST OF SYMBOLS}

A Cross-sectional area in $\mathrm{mm}^{2}$

$A_{i} \quad$ Area of member $i$ in $\mathrm{mm}^{2}$

C

Operating center distance in $\mathrm{mm}$

$\mathrm{C}_{\mathrm{a}}$

Application factor for pitting

$\mathrm{C}_{\mathrm{c}}$

curvature factor at pitch line

$\mathrm{C}_{\mathrm{f}}$

Surface condition factor for pitting

$\mathrm{C}_{\mathrm{g}}$

Constraint set for the design process

$\mathrm{C}_{\mathrm{m}}$

Load distribution factor for pitting

$\mathrm{C}_{\mathrm{p}}$

Elastic coefficient in [MPa $]^{\frac{1}{2}}$

$\mathrm{C}_{\mathrm{s}}$

size factor for pitting

$\mathrm{C}_{\mathrm{v}}$

Dynamic factor for pitting resistance

$c_{x}$

contact height factor

$C_{\phi}$

Helical overlap factor

d

operating pinion pitch diameter in $\mathrm{mm}$

$d_{i}$

Diameter of member $i$ in $\mathrm{mm}$

$d_{m}$

Mean diameter of ring in $\mathrm{mm}$

$d_{p}$

Pitch diameter of pinion in $\mathrm{mm}$

E

Modulus of Elasticity in $\mathrm{MPa}$

$E_{p}, E_{g}$

Modulus of

elasticity of

pinion

and

gear respectively

Value of function evaluated in each epoch

$F_{t}$

Force in $\mathrm{N}$

Facewidth in $\mathrm{mm}$ 


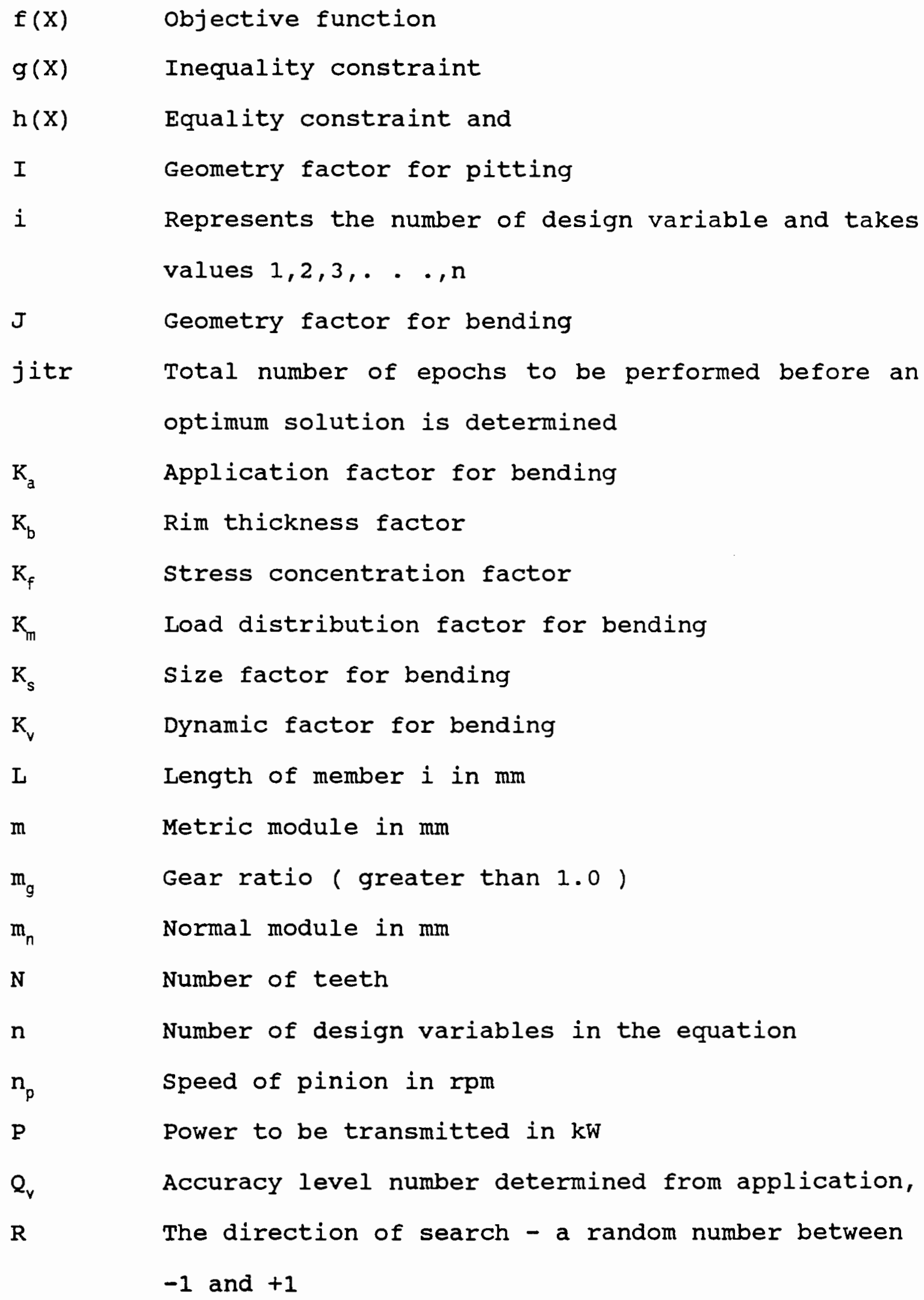


Value of design variables in iteration [itr-1]

$S_{c}$

$S_{t}$

$S_{y}$

$S^{\prime}$

$t$

$\mathrm{V}$

vt

W

$\mathbf{W}_{\mathrm{t}}$

$x_{i}$

$x_{1 i}$

$x_{u i}$

$\mathrm{Y}$

$Y_{\max }$

$\alpha_{i t r}$

$\delta$

$\delta_{i}$

$\mu_{p}, \mu_{g}$

$\rho$

$[\sigma]$

Contact stress in $\mathrm{MPa}$

Bending stress in $\mathrm{MPa}$

Permissible yield strength of member $i$ in $\mathrm{MPa}$

Value of design variables in iteration [itr]

Diameter of wire in $\mathrm{mm}$

Volume in $\mathrm{mm}^{3}$

Pitch line velocity at operating pitch diameter in $\mathrm{m} / \mathrm{s}$

Weight in $\mathrm{kg}$

Transmitted load in $\mathrm{N}$

Design variable

Lower bound design variable $x_{i}$

Upper bound on design variable $x_{i}$

Tooth form factor

Maximum allowable deflection in the horizontal and vertical directions in $\mathrm{mm}$

The step size in the $i t r^{\text {th }}$ iteration in a particular epoch

The magnitude of change associated with step size in a particular iteration

A small value

Poisson's ratio for pinion and gear respectively

Density of material in $\mathrm{kg} / \mathrm{mm}^{3}$

Maximum allowable stress in MPa

Calculated stress in $\mathrm{MPa}$ 
xii

Helix angle in degrees 


\section{CHAPTER I}

\section{BACKGROUND}

\subsection{OPTIMIZATION}

Optimization is essentially a branch of applied mathematics dealing with techniques of achieving the "best" or the "most favorable" solution for a problem. Optimization techniques involve analytical, experimental and numerical tools [Arora,1]. All three techniques have been successfully incorporated in the design of structural elements. Of late, optimization techniques are being used in almost all fields of engineering, however aerospace engineering has been predominant in using optimization techniques.

With the concept of modern manufacturing techniques and the growing awareness about the limitation in the availability of raw materials and other resources, it has become essential for design engineers to work with design constraints for an efficient and cost effective system. Conventionally design processes have depended upon the "expertise" and intuition of the individual designer. Lack of ability to "search" for the optimum or the best design manually, led to the use of mathematical techniques. Optimization involves the use of a wide range of linear algebra and differential calculus techniques. Typically, an optimization method would involve 
the determination of the change in value of a function, step size and the direction of search, besides problem formulation and identification constraints and design variables which are discussed in detail later.

The earliest optimization techniques that were used for searching the best solution were of the partitioning or the sectioning method, where search was conducted for the best solution in small segments, in a given domain. For a given objective, the variables in the problem are manipulated mathematically, within a specific region. The classical method that uses this technique of partitioning, for solving one dimensional problem to achieve an optimum is the golden section search [Arora,1].

overwhelming use of human element in the design process has led to dangerous and erroneous results in the synthesis of complex systems. The conventional design process involves the use of information gathered from one or more trial designs along with the intuitive knowledge and experience of the designer. In contrast, optimum design process involves not only the benefits that could be obtained from "intuitive knowledge and experience, but also the advantages of analysis, simulation and optimization" [Arora,1]. The above contrast between the conventional and optimum design process is true only when the complete sequence of design has been implemented on a computer. Figures 1 and 2 [Arora,1] highlight the sharp contrast between the conventional and optimum design 

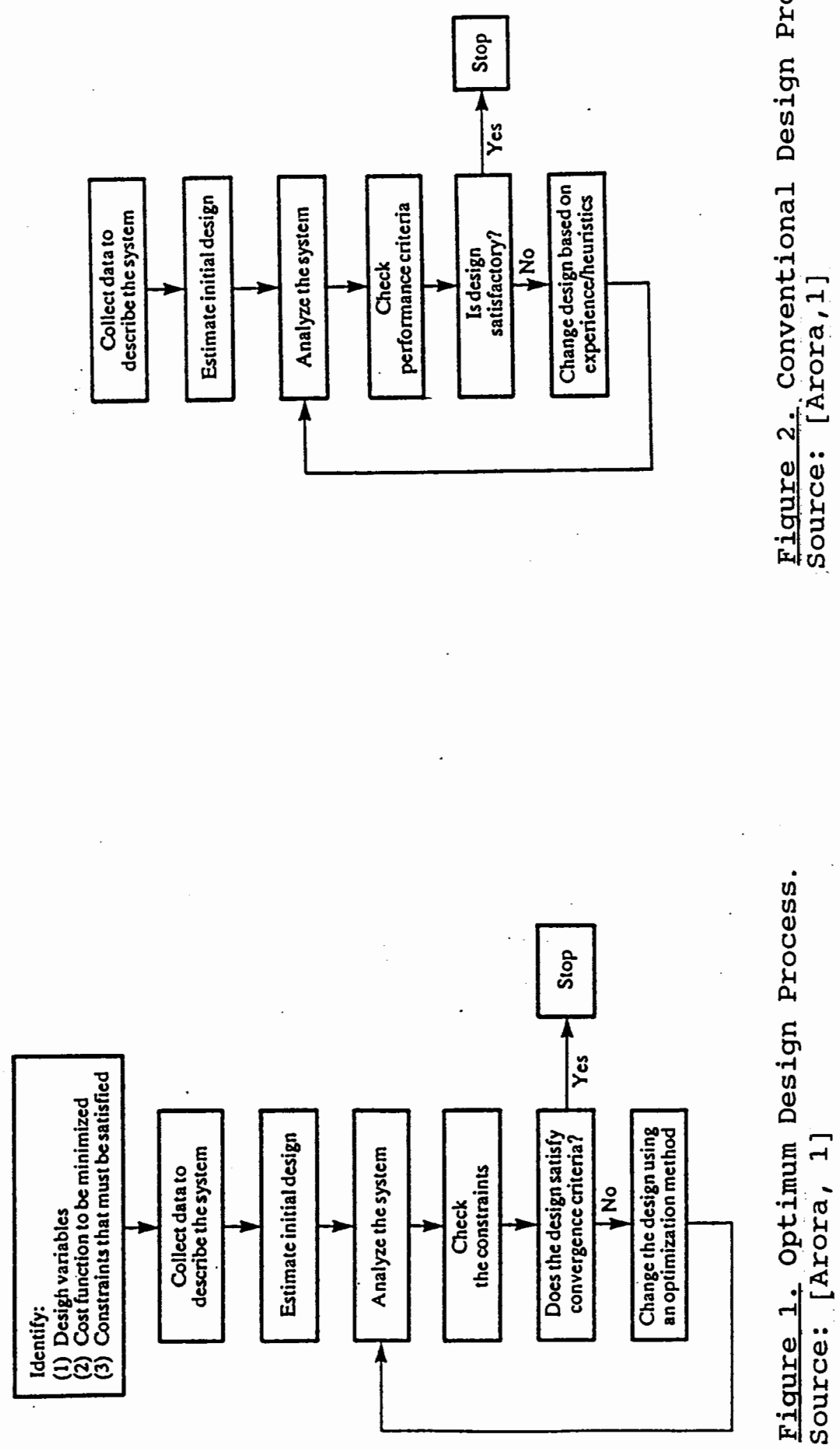
processes.

Conventional and optimum design processes could be used at different stages of design. For example, consider the design of a transit system between areas of Portland metropolitan and the neighboring west side of Portland. To choose among a diesel powered railroad, an electric train or a magnetic levitation rail system is at the discretion of the system designer. However when it comes to the design of details such the dampers, the wheels, the brakes and other components, the designer does not choose them at his/her own discretion. A series of formulas to design and analyze the system are used for this purpose. The design usually starts with the selection of a few parameters, generally obtainable from previous records or experience. Following the design stage, the analysis stage would involve the use of several complex equations, usually non-linear of higher order to determine whether the design is acceptable or not. The use of optimization techniques in such instances would prove to be effective, as against any human activity to achieve the goal, especially due to the fact that it is more organized and methodical in achieving a solution.

In conventional design process no effort is made to minimize or maximize any of the functions of the system as it would be a very tedious computational process. Optimum design methods are likely to reduce lead times sizably due to the absence of human element in the process of maximizing or 
minimizing a function.

In order to achieve a prudent problem formulation, it is necessary to limit the domain of the problem to essential factors. For the example above, it would be a futile effort not to consider the effect of rain and hence rusting of several parts while it would also be unnecessary to try and develop a design that would best fit the transit system's schedule. Identification of the constraints and design variables has to be done carefully so that the system is completely defined.

\subsection{OPTIMIZATION IN MECHANICAL DESIGN}

As discussed earlier in this section, conventional methods can no longer be considered efficient approaches for design. Most of the currently available design procedures for design of mechanical components are based on discrete values and several of the designs have been computerized. Because of the discrete nature of design, it has been regarded that optimization cannot be used in design of mechanical components where continuously differentiable functions are uncommon. However, the advent of computer-aided-design (CAD) has helped in breaking the shell around optimization. Continuously differentiable functions are discretized into a database and assumed to be a sequence of numbers, arranged in the continuous order. For example the module of a gear is a set of discrete values. They can be stored in a database and ordered 
from 1 to $n$ with an increment of 1 . Now the set of modules have been made continuous between 1 to $n$. As an example, Table I shows how this is done. By doing so, the variable module is assumed to be continuous and whenever the variable is incremented or decremented the corresponding discrete value is read from the database and is used in the optimization process.

\section{TABLE I}

DISCRETE VALUES REPRESENTED CONTINUOUSLY

\begin{tabular}{|c|c|}
\hline $\begin{array}{c}\text { Pseudo continuous } \\
\text { values for module }\end{array}$ & $\begin{array}{c}\text { Discrete values } \\
\text { of module }\end{array}$ \\
\hline 1 & 1.25 \\
2 & 1.50 \\
3 & 1.75 \\
4 & 2.00 \\
5 & 2.25 \\
6 & 2.50 \\
7 & 3.00 \\
8 & 3.50 \\
. & $\ldots$. \\
\hline
\end{tabular}

\subsection{COMPUTERS IN OPTIMAL DESIGN}

Analysis of mechanical systems have become more detailed with the use of computers. This allows us to understand the behavior of systems to a higher level of detail, more efficiently. Moreover, iterative and repetitive procedures are much simplified with computers. Analysis of a system at each stage during its design process produces only few solutions after several complicated calculations. With the advent of 
optimization in the design process, the intensity of computation has increased many times. Hence it is judicious to conclude that optimal design could be more efficient with the use of computers. However this should not lead one to conclude that computers are intelligent, while they are still incapable of making any decision! Optimization involves great amount of looping and repetitive calculations.

\subsection{DEFINITION OF PROBLEM FOR OPTIMIZATION}

It is a generally accepted fact that the correct formulation of a problem takes roughly $50 \%$ of the total effort needed to solve the problem [Arora,1]. A typical problem in optimization has an objective function, constraints and design variables. The objective function might define efficiency, volume, weight, power or torque. This function, depending on the use, may be required to be maximized or minimized. The objective function is a mathematical formulation of the desired end result. It is also the criterion function that is used to select the best of the feasible solutions. For example the following are objective function in their own domain, - a pump manufacturer may want to maximize the efficiency of the pump, a machine manufacturer may want to minimize the cost of the equipment, or a truck manufacturer may want to maximize the power of the truck. The objective function is the easiest to formulate in the process of optimization. Identifying the objective is a decision that has to be taken by a responsible 
person. Once the objective is defined, the factors that could restrain one from achieving the objective - referred to as the constraints are formulated.

The constraints are difficult to identify, in contrast to the objective. Problems should neither be over-constrained nor under-constrained. For example in designing a ball bearing it would be superfluous to formulate a constraint for buckling load. Similarly the whole process of optimization would be a failure if the effect of radial load were to be neglected for its design. Constraints are of two kinds. The first is a limiting equation and (in mechanical design) most often is stress related, temperature related or size related [Arora, 1]. The second type of constraints, side constraints, are those that impose bounds on the design variables. The constraints delineate feasible and infeasible solutions which may either be implicit or explicit. Constraints must be represented in terms of variables defined as design variables.

All those variables that influence the systems' characteristic during optimization are called design variables. They are also the parameters chosen to describe the design of a system. Once values are assigned to each of these variables, a system design is known and these design variables are required to lie within a range. It may not be necessarily true that all combinations of design variables would yield feasible solution. Figure 3 is a pictorial representation of the design space. The space indicated as feasible design 
represents the space in which design is viable.

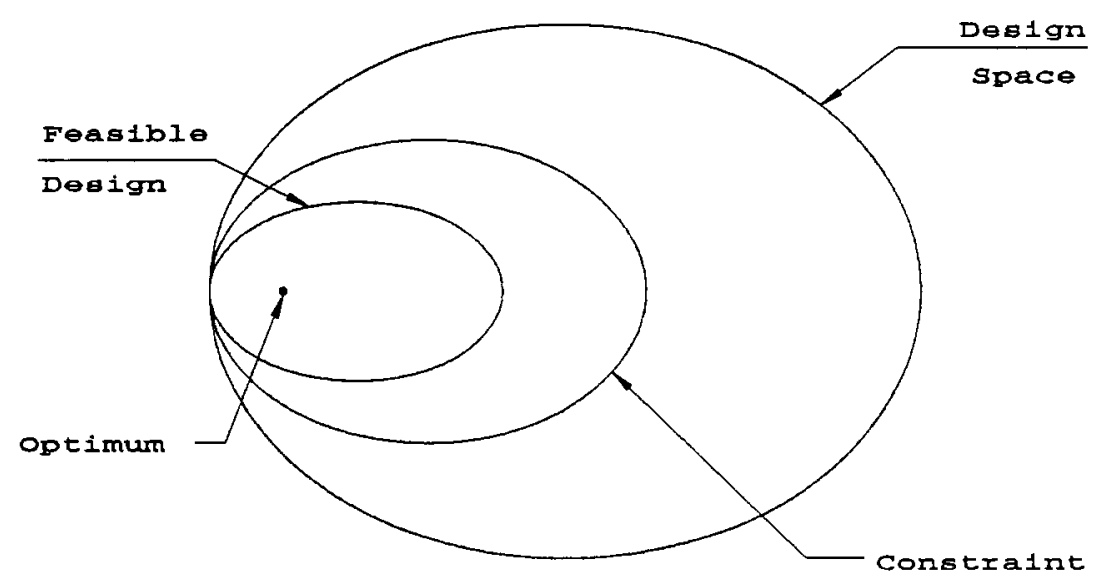

Figure 3. Design space.

1.5 OPTIMAL DESIGN OF GEARS

Among the class of transmission elements, gears form an important family. Their complex shape, geometry and characteristics, make their detailed design process tedious. Gears are selected based on the application. The dimensions of the gear have thus far been determined based on certain "rule of thumb" expressions. Traditionally, gears have been designed by "experts". A typical gear design would involve computation based on the final shape, form, strength, accuracy, noise and efficiency. To avoid the complexity in calculations, large factors of safety are used which result in bulky gears. The necessity for compact, efficient and safe gears make it necessary for a designer to use optimization techniques. 


\subsection{OBJECTIVE OF THIS PROJECT}

Gear design involves complex, non-linear equations. Usually gears are designed to withstand bending and contact stresses. Depending on the need, design may also include noise reduction, life determination and efficiency. Not much research has been done in the optimal design of machine elements except in the field of kinematics. The first paper on the optimal design of gears was published in 1984 by carroll and Johnson $[2,3]$. There has not been much work that has been reported since then.

The constraints in the process of gear design are nonlinear. Due to the complexity of these equations it is infeasible to implement a sequential linear programming technique or a gradient based method, as the true nonlinearity of the problem is lost. Lee and Freundstein [11, 12] and Schumer and steiglitz [15] have shown that for problems that are highly non-linear and dimensionally large, random search methods are likely to yield better solution than any of the conventional algorithms.

In this project, a random search strategy is developed and used for the optimal design of helical gears. This work focuses on the capability of random search in producing "acceptably" good solution and at the same time maintaining the non-linearity of the problem. The strategy used in the random search algorithm is to generate as many feasible solutions as possible and to determine the best solution from 
the set of feasible solutions. An attempt has been made to incorporate the state-of-art techniques in interactive optimization, which is a relatively new field of research. The project also includes the comparison of the random search with a successive quadratic programing (SQP) based algorithm. 
CHAPTER II

RANDOM SEARCH ALGORITHM FOR OPTIMIZATION

Like most optimization techniques the random search is also an iterative algorithm. It differs from the rest in that it is not a deterministic numerical method, but an orderly search in random directions. Random search techniques may sometimes be too slow to reach an optimum if one exists. As against the complexity of the deterministic numerical methods like linear programming and gradient descent algorithms, random search is a fairly straightforward technique and is likely to give approximate solution faster than the conventional optimization methods for nonlinear programming problems. The other major difference between the conventional algorithms available for nonlinear problems and the random search is that the latter does not use a linearization strategy to solve the problem.

\subsection{NUMERICAL METHODS IN OPTIMIZATION}

Numerical optimization techniques offer a logical approach to design automation [Vanderplaats, 18]. Numerical methods are widely used to solve nonlinear problems because the analytical methods turn out to be a cumbersome process, involving repeated calculation of the gradient, partial derivative and 
value of the function and constraint at every iteration. The major reasons why numerical methods are preferred over analytical methods [Arora,1] are,

1. The number of design variables and constraints can be larger

2. The functions for design variables can be non-linear, and 3. Cost and or constraint functions can be implicit in terms of design variables.

several systematic numerical methods have been successfully programmed to solve optimization problems. A typical optimization problem is represented as shown below,

$$
\begin{array}{ll}
\text { Minimize } & f(X) \\
\text { Subject to } & h(X)=0 \text { and } \\
& g(X) \leq 0
\end{array}
$$

where $x=\left\{x_{1}, x_{2}, \ldots x_{i}\right\}$, and each $x_{i}$ is bounded by an upper and lower limit,

$f(x)$ objective function,

$h(X)$ equality constraint and

$g(X)$ inequality constraint

In general, a constrained optimization problem includes the determination of step size and the search direction. Most of the optimization techniques are based on linearization if the problem happens to be nonlinear. Linearization of problems could be interpreted as simplifying the model of the system to be optimized, for the purpose of easier calculation. However, to achieve a good solution it is essential that the problem be 
treated as defined. When highly non-linear problems, as in the case of gear design, are considered, it becomes a difficult task to perform deterministic numerical optimization. Random search technique is slower in computation than a linearized model. On the other hand, random search method is better than a nonlinear optimization algorithm as it would give a solution faster, and it will be a good approximation for use as a starting solution in the deterministic numerical methods. With such an attribute, random search technique is a good trade off between the linearization method and non-linear method, especially when the problem is of larger dimension and starting solution are difficult to identify. Random search algorithms are not too complex, however the critical point to be borne in mind in developing a random search strategy is to keep the computation clear of any possible incorrect manipulation and providing an appropriate termination criteria. A major advantage with random search methods is that, unlike the deterministic numerical methods they are not dependent on starting solution, in the sense that they would give a solution that would be close to the global optimum. This means that the solution obtained for every starting point will be deviant from one another by some value.

Optimization In Mechanical Engineering Design: An Example

A typical optimization problem in design is shown in figure 4. It is required to design a ring for minimum volume. The ring has a circular cross-section, and is subjected to a 
force $F$, equal in magnitude and opposite in direction. It is required to minimize the volume of the ring, subject to constraint of simple stress.

The objective function for the problem is,

$$
V=\left(\pi d_{m}\right) \frac{\pi t^{2}}{4}
$$

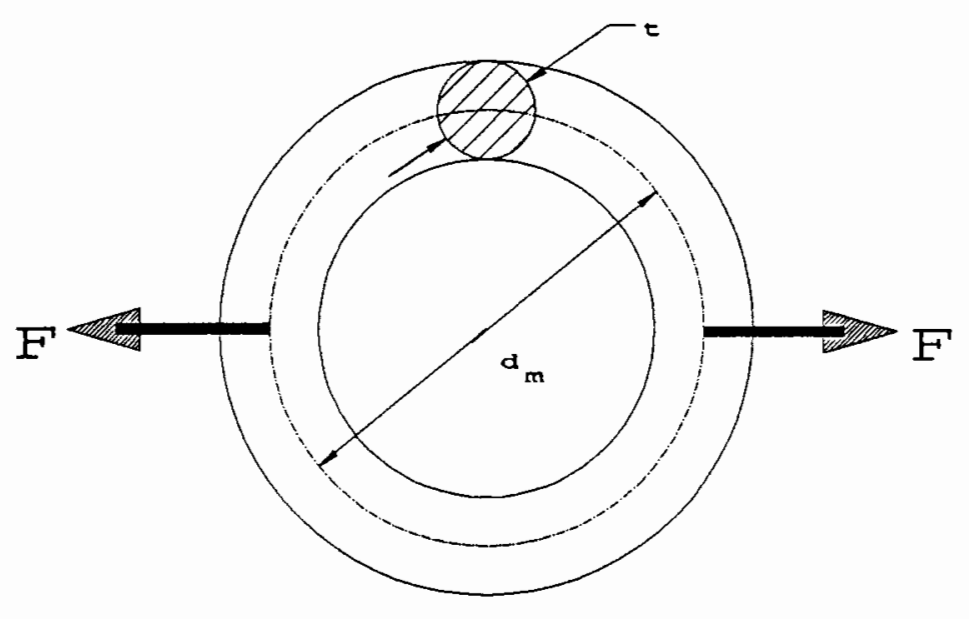

Figure 4. A circular ring in tension.

The constraint is,

$$
\sigma=\frac{F_{t}}{A}=[\sigma]
$$

where,

$[\sigma]$ is the maximum allowable stress

$\sigma$ is the calculated stress

The design variables in this problem are, the wire diameter ' $t$ ' and the mean radius $d_{m}$. Bounds on these design variables are,

$$
\begin{aligned}
& d_{m}, t>0 \text { and } \\
& d_{m} / t<8.0
\end{aligned}
$$




\subsection{TERMINOLOGIES AND NOTATION}

The following terminologies are introduced for random search techniques.

Epoch :

One complete iteration or search performed for a particular random number.

Iteration : Each time a step size is altered.

step size: The magnitude by which the value of the variables are changed in every iteration.

Direction of: A random number generated between -1 and +1

search (equivalent to the slope of a straight line). Violation of : The magnitude by which the value of the constraint constraint is away from the permissible value.

\subsection{RANDOM SEARCH METHODS}

Most random search methods use a random number generated between -1 and +1 as the search direction. By doing so, and adopting a line search, a point can be moved in all $360^{\circ}$. Consider a problem in which $f(X)$ has to be minimized and $f(X)$ is a problem of $\Pi$ dimensions. This can be considered as a problem in a hyperspace of $I$ dimensions, where,

$$
x_{1 i}<x_{i}<x_{u i} \text {, }
$$

and

$$
\begin{aligned}
& x_{i} \text { design variable } \\
& x_{1 i} \text { lower bound design variable } x_{i} \\
& x_{u i} \text { upper bound on design variable } x_{i}
\end{aligned}
$$

The simplest concept of random search in a hyperspace is 
to generate a set of random numbers uniformly distributed between 0 and 1 in either direction and compute the corresponding values of design variables using a linear equation [Jacoby, Kowalick and Pizzo,9]. After performing a certain number of iterations using a random number, the search is limited to some neighborhood space of the most successful points in the previous iterations. By doing so the number of function calls are minimized and speed of achieving a solution is increased, but the amount of risk in over shooting the optimum exists due to the large step size. In order to avoid such a situation, a series of searches with different random numbers is conducted and a set of solutions called the set of feasible solutions is generated. The set includes the optimum solution obtained in each of the random directions. The best among the set of feasible solutions is likely to be the optimum for the problem.

Three of the commonly used random search techniques in solving kinematics problem, and their deficiencies for the present problem are briefly discussed below.

\section{Adaptive Random Search}

This method uses a certain "bias" factor from previous experience besides the random number and the step size. starting with a known "bias" factor, subsequent "bias" factors are computed as a linear combination of the previous step size and "bias"[25]. Due to lack of any prior knowledge of best "bias" factors this method is not used for the present problem. 


\section{Adaptive Step Size Random Search}

This method is an enhancement of the adaptive random search and was developed by schumer and steiglitz [15]. This method uses an "optimized" step size that is obtained as a result of "exploratory" searches conducted in random directions. Step sizes that seem to achieve the objective are used as optimized step sizes for the next iteration till a termination criterion is reached. Several such searches are conducted and the best solution is obtained from a set of feasible solutions. This kind of random search is more systematic and by using sufficiently large iterations it is likely that an optimum would be found. The authors of this algorithm have shown for their problem that, random search methods is superior to conventional nonlinear problem solving methods. Although this algorithm has no major drawback, memory requirements are very high.

\section{Combinatorial Heuristic Method}

This method was primarily developed for problems in control engineering at AT\&T laboratory. Lee and Freundstein [11] have successfully implemented this algorithm for their kinematic analysis problem [12]. This method uses the discrete nature of design variables and then carries out a random search over a resulting finite grid of possible solutions. Variables are selected one at a time and their feasibility is checked, which makes the technique a tedious process requiring large amounts of memory. 
Based on the adaptive step size random search and the combinatorial heuristic method a new algorithm called the modified adaptive step size random search has been developed and implemented by this author. The current algorithm differs from the rest, in that it uses the value of the gradient to determine the direction and magnitude of change of step size.

\subsection{THE MODIFIED ADAPTIVE STEP SIZE RANDOM SEARCH}

\section{The Approach}

For problems of larger dimension there are generally a substantial number of feasible solutions. However there is no set procedure or method that would help in achieving a unique solution. To avoid any discrepancy of optimum solution it is therefore best to find as many feasible solutions as possible, and each of those solutions would be a good approximation of the optimal solution. Determining a number of solutions means more time is required for determining the best solution. The random search algorithm that has been developed decreases the time required for reaching an optimal solution by using a step size that is adaptively varied by determining the value of the constraint. By stepping over or stepping less, violation of the constraint is determined and the step size is altered to minimize the violation. This method proves to be effective for problems of large dimension where it might be cumbersome to perform a conventional optimization, using Hessian and 
gradient.

\section{The Algorithm}

The random search method that is developed does not use any calculation of derivatives. Therefore the method is strictly a non-deterministic numerical one. The basic approach is that, given a starting solution, a search is conducted in several random directions, in the feasible region. If the starting solution is outside the feasible region, the variable is brought into the feasible space by changing the step size and continuing the search. Depending on the random direction a minimum may be achieved. All such solutions form the set of feasible solutions. By performing a large number of searches, a global minima might be determined. The best of the set of feasible solutions is presented as the optimum.

The steps below indicate the sequence of the modified adaptive step size random search algorithm.

1. Generate a set of starting solution for $n$ variables. The starting solution $S$, need not be in the feasible region.

2. Generate a random search direction, $R$ and obtain a new set of solution $S^{\prime}$ such that it minimizes the constraint violation. If the solution is not found and if the constraints are not violated increase the stepping size $\alpha_{i t r}$ and continue to search until a solution is determined or a constraint $\mathrm{C}_{\mathrm{g}}$ is violated. Upon violation of the constraint, the magnitude of stepping size is reduced by $\delta$ and the direction of stepping is reversed. This process 
of determining an improved solution $S^{\prime}$ over $S$ is continued until the constraints fall within acceptable values, as specified by the design requirements. The value of the objective function at the best $S^{\prime}$ (with minimum value of objective function) is determined as F.

3. Generate a new random search direction and repeat step 2 .

4. Until a stopping criteria 'jitr' is reached, feasible solutions are generated in every possible direction. The best of the set of feasible solution is the optimum solution. This is determined by finding the minimum or the maximum of the value of the objective function during each "epoch", as necessary.

where,

$\mathrm{n}$ number of design variables in the equation

$s$ value of design variables in iteration [itr-1]

S' value of design variables in iteration [itr]

F value of function evaluated in each epoch.

$\mathrm{R}$ the direction of search - a random number between 1 and +1

$\alpha_{i t r}$ the step size in the itr ${ }^{\text {th }}$ iteration in an epoch

$\mathrm{C}_{\mathrm{g}}$ constraint set for the design process

jitr total number of epochs to be performed before an optimum solution is determined

$\delta \quad$ the magnitude of change associated with step size in a particular iteration 


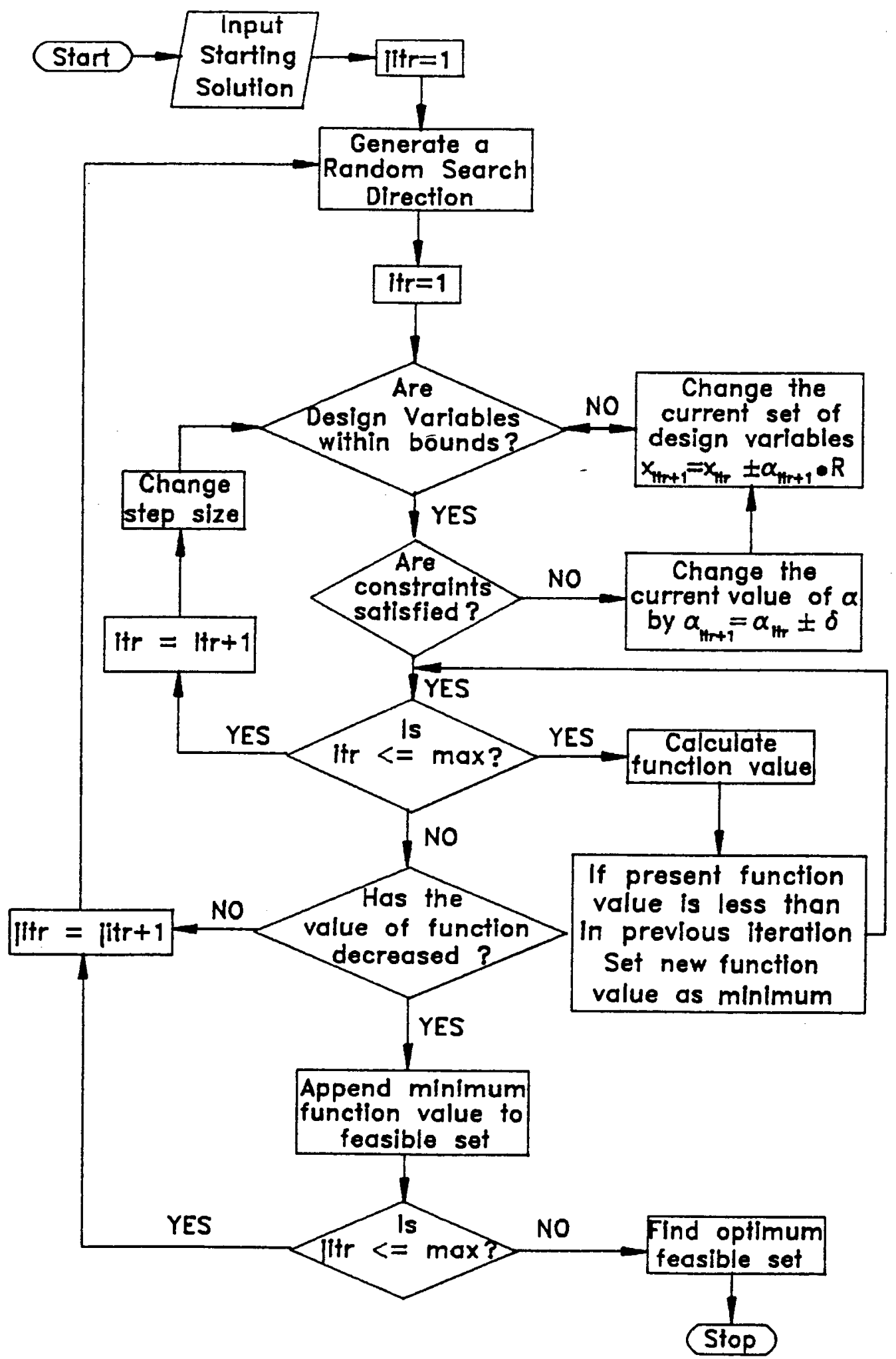

Figure 5. Flowchart for the Modified Adaptive Step Size Random Search Technique. 
The set of feasible solutions is actually a set of minima achieved in each random search direction. Hence, as one can guess the solution is dependent on the random search direction and the number of searches conducted in each of the directions. Figure 5 shows the flow chart of the random search technique developed. Random search techniques do not require large memory capacities due to the absence of any deterministic numerical method, and thus do not impose a limitation on the number of constraints that can be used for the design process.

The critical factor in the use of a random search algorithm is the definition of the stopping criterion. The stopping criteria is usually the number of random directions generated and the number of searches conducted in each direction. If no optimum is found, the number of iterations to be performed to yield an optimum has to be increased. Or, if only very few optimum are found it is again necessary to increase the number of iterations to ensure that a global minimum is reached.

\section{Mathematical Representation of The Random Search}

The random search is a line search in a given random direction. The random direction is given by $R$, the design variables are given as $x_{i}$ and the step size is $\alpha_{i t r^{*}}$ To begin with, the design variables are checked against their bounds. If the variables are not within the bounds then one of the following steps is adopted. 


\section{Case(a)}

If the design variable is less than the lower bound,

$$
\begin{aligned}
x_{i} & =x_{i}+\alpha_{i t r} R \text {, if } R \text { is positive, } \\
\text { else, } x_{i} & =x_{i}-\alpha_{i t r} R, \text { if } R \text { is negative. }
\end{aligned}
$$

Case (b)

If the design variable is greater than the upper bound,

$$
\begin{aligned}
x_{i} & =x_{i}-\alpha_{i t r} R \text {, if } R \text { is positive, } \\
\text { else, } x_{i} & =x_{i}+\alpha_{i t r} R \text {, if } R \text { is negative. }
\end{aligned}
$$

All four variables need not necessarily undergo the above mentioned changes simultaneously.

once the variables are within bounds the constraint is evaluated. Based on the value of constraint one of the following steps is adopted. $\delta$ is a value causing change in step sizes.

\section{Case (a)}

If the constraint is not violated and is lower than the permissible value,

$$
\begin{aligned}
\alpha_{i t r+1} & =\alpha_{i t r}-\delta, \text { if } R \text { is positive } \\
\text { else, } \alpha_{i t r+1} & =\alpha_{i t r}+\delta, \text { if } R \text { is negative. }
\end{aligned}
$$

$\underline{\text { Case (b) }}$

If atleast one constraint is violated,

$$
\begin{aligned}
\alpha_{i t r+1} & =\alpha_{i t r}+\delta, \text { if } \mathrm{R} \text { is positive } \\
\text { else, } \alpha_{i t r+1} & =\alpha_{i t r}-\delta, \text { if } \mathrm{R} \text { is negative. }
\end{aligned}
$$

If constraint violation changes sign, the design variables are assigned the values from the previous iteration and the step size is halved, until the constraints are satisfied. The 
function values are calculated only when the constraints are satisfied, and is added to a set of feasible solutions. The complete process described above is repeated for different random numbers until either the termination criteria is satisfied or the process is interrupted by the designer. The optimal solution is that set of design variables for which the function has minimum value.

\section{Graphical Interface}

In order for the optimization to be effective it is necessary that the user or the designer continuously monitor the behavior of each of the design variables so that suitable variations like changing a design variable to a constant, or removing a constraint after certain iterations, can be accomplished during the optimization process. A graphical interface to optimization is still a field of active research.

In the present work, an interactive graphical interface has been provided to a limited extent. The user can monitor the design process, can interrupt the design process and change the input parameters or can interrupt the optimization to exit to get the results achieved until the optimization process was interrupted. The interface between the optimization process and the designer is a set of graphs plotted between the epoch number and the value of each design variable when the constraint violation is minimum during that epoch. Figure 6 shows the graphs that are presented to the user. 


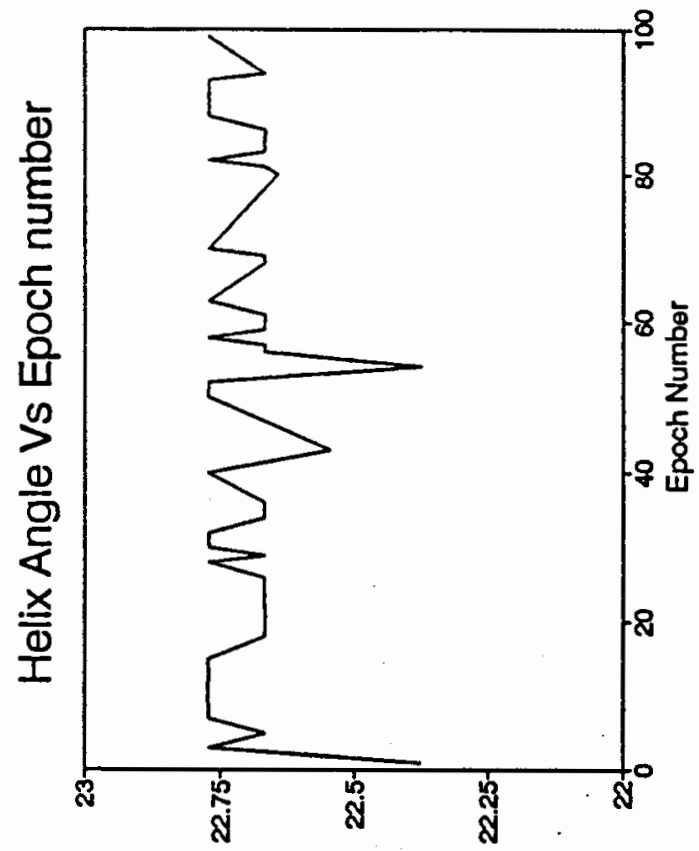

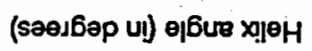

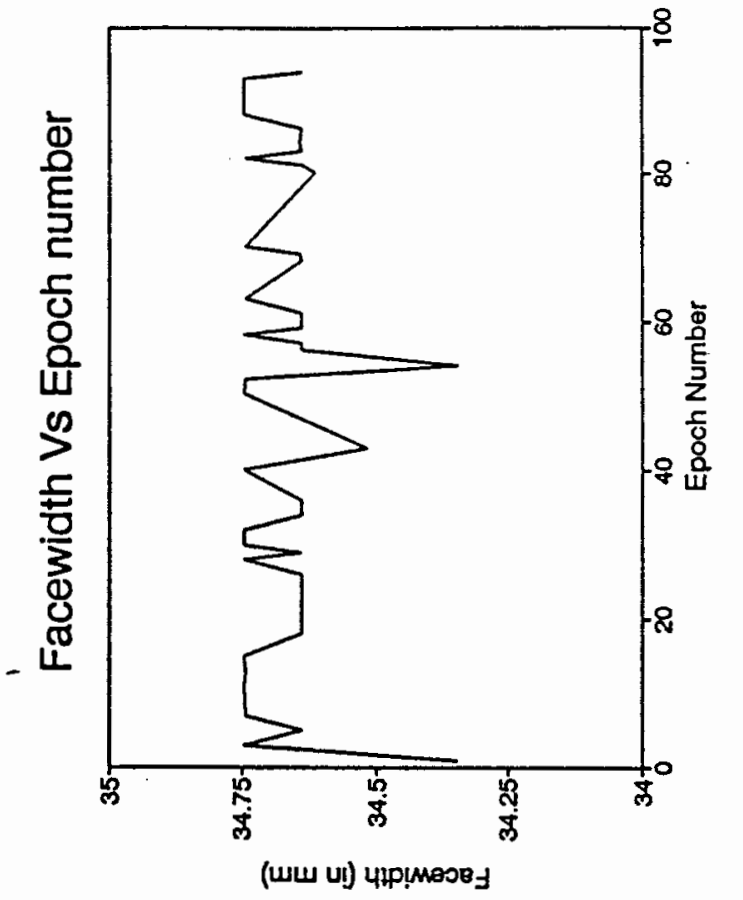

ב 4
0
0 0 in

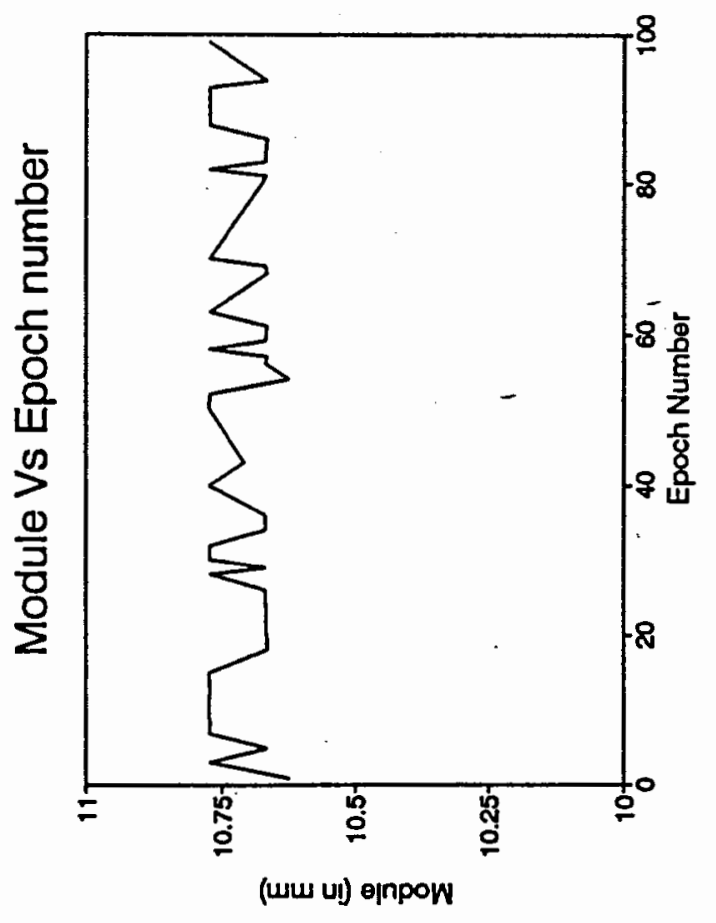

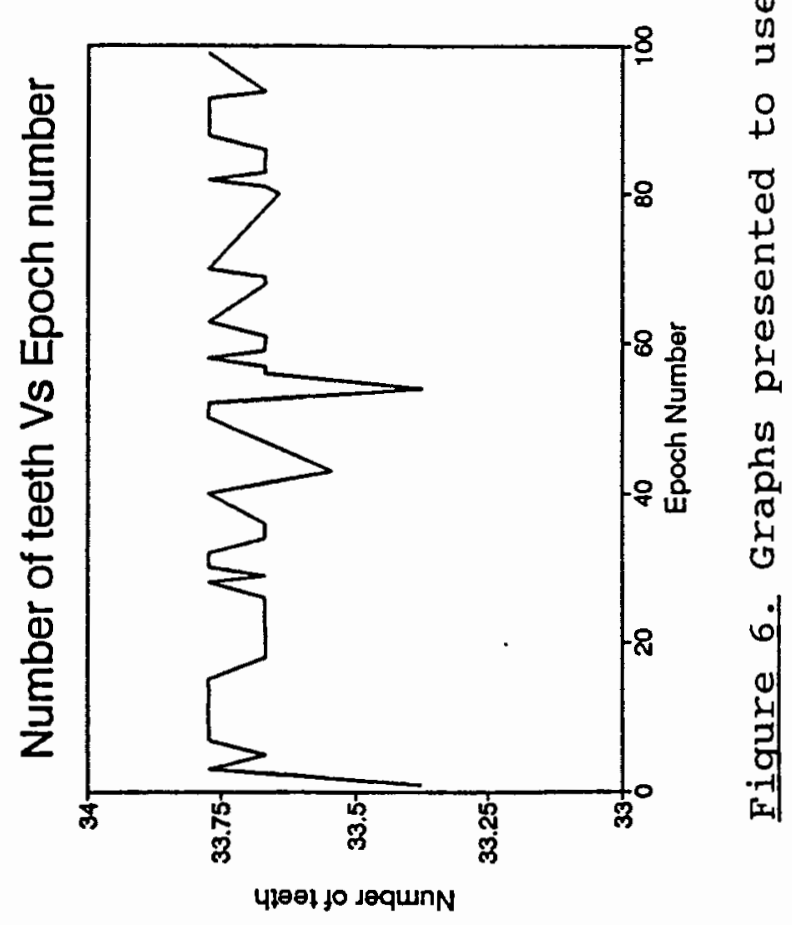


one of the major problems with random search methods is that they would minimize the problem fully, i.e., to an extent where design may not be practically possible. In order to help the designer change the value of a variable at a particular point i.e., to either make a variable constant or change its value, interactive optimization is essential. Although this level of implementation, where the user can stop the optimizing process or change the state of one or more of the variables, has not been achieved, some amount of this aspect of interactiveness has been incorporated in the algorithm.

The random search method is also available as a user callable program. Appendix B gives a brief listing of how to use this method by just defining the functions and constraints separately. There is no graphical interface to this module. 


\section{APPLICATION OF RANDOM SEARCH TO} OPTIMAL DESIGN OF HELICAL GEARS

The random search algorithm has been tested on two different problems, before being implemented for the design of Helical gears. A generic constrained non-linear optimization problem was tested against known results and were found to be satisfactory. Eq 3.1 defines the objective function for the problem and eq $3.2,3.3$ are the constraints. The bounds on the variables are simple and are given in eq 3.4. Table II shows a comparison of the values of design variables obtained by the random search and those obtained by a gradient based algorithm, available in the IMSL library of optimization routines [24].

$$
\begin{array}{r}
\text { Minimize } f(x)=\left(x_{1}-2\right)^{2}+\left(x_{2}-1\right)^{2} \ldots \ldots 3.1 \\
\text { Subject to } g_{1}(x)=x_{1}-2 x_{2}+1=0 \\
g_{2}(x)=-x_{1}^{2} / 4-x_{2}^{2}+1 \geq 0 \\
-1 E 06<x_{1}, x_{2}<1 E 06 \quad \ldots 3.2
\end{array}
$$

The random search technique was also tested for a threebar truss problem with the objective of achieving minimum weight. Figure 7 shows the structure and the associated parameters. Eq 3.5 gives the objective function and Eq. 3.6 to 3.8 are the constraints. The random search was implemented for two different sets of constraints - one, for two elements 1 
and 3 with identical properties and the other for all elements TABLE II SOLUTION FOR THE NONLINEAR MINIMIZATION PROBLEM

\begin{tabular}{|c|c|c|c|}
\hline & & $\begin{array}{c}\text { Gradient based } \\
\text { Algorithm }\end{array}$ & $\begin{array}{l}\text { Random search } \\
\text { Algorithm }\end{array}$ \\
\hline \multirow{2}{*}{$\begin{array}{l}\text { Starting } \\
\text { Solution }\end{array}$} & Variable $\times 1$ & 2.00 & 2.00 \\
\hline & Variable $\times 2$ & 2.00 & 2.00 \\
\hline \multirow{2}{*}{$\begin{array}{l}\text { Final } \\
\text { Solution }\end{array}$} & Variable $\times 1$ & 0.8229 & 0.8317 \\
\hline & Variable $\times 2$ & 0.9114 & 0.9201 \\
\hline \multicolumn{2}{|c|}{ Value of objective fn. } & 2.1700 & 2.0033 \\
\hline \multicolumn{2}{|c|}{ Approximate time } & 40 seconds & 8 minutes \\
\hline
\end{tabular}

Specifications for the three bar truss problem

- Permissible stress for members is $80 \mathrm{MPa}$

- Area of member 1 and 3 are equal

- Modulus of Elasticity for 1,2 and $3=210 \mathrm{MPa}$

- Member 1,2 and 3 are of the same material

- Objective is to minimize

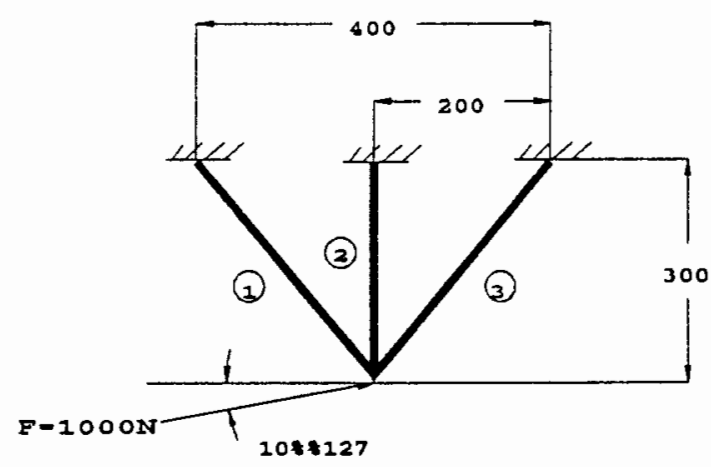
the diameter of the members

Figure 7. Three bar truss problem. 
having different properties. The result of the optimization are shown in Table III. The three bar problem could not be implemented with the gradient based technique as the starting solution could not be defined within the feasible region. The result for the three bar optimization using the random search method was obtained by a fellow Graduate student for a class project [8]. The problem was defined as follows, Objective: To minimize the volume of the three bar truss,

$$
\mathrm{V}=\sum \text { Area }_{i} L_{i}
$$

Subject to,

Yield:

$$
S_{y i}-\frac{f_{i}}{A_{i}}=\delta_{i}
$$

Deflection:

$$
\mathrm{Y}_{\max }-\mathrm{U}=\delta_{2}
$$

and Buckling:

$$
\frac{\pi^{2} E y A_{i}^{2}}{L}+f_{i}=\delta_{3}
$$

where,

$$
\begin{aligned}
& i=1 \text { to } 3 \\
& V=\text { Volume in } \mathrm{mm}^{3} \\
& A_{i}=\text { Area of member } i \text { in } \mathrm{mm}^{2} \\
& \mathrm{~L}=\text { Length of member } i \text { in } \mathrm{mm} \\
& \mathrm{d}_{i}=\text { Diameter of member } i \text { in } \mathrm{mm} \\
& \mathrm{s}_{y}=\text { Permissible yield strength of member } i \text { in MPa } \\
& Y_{\max }=\text { Maximum allowable deflection in the horizontal and } \\
& \text { vertical directions in mm }
\end{aligned}
$$


$\mathrm{E}=$ Modulus of Elasticity in $\mathrm{MPa}$

$\delta_{\mathrm{j}}=\mathrm{a}$ small value

The design variable in the problem is the diameters of the members in the truss.

TABLE III

SOLUTION FOR THE THREE BAR TRUSS PROBLEM

\begin{tabular}{||l|r|c||}
\hline & $\begin{array}{c}\text { Starting } \\
\text { Solution }\end{array}$ & $\begin{array}{c}\text { Final } \\
\text { Solution }\end{array}$ \\
\hline Dia. of member 1 & $18.00 \mathrm{~mm}$ & $4.05 \mathrm{~mm}$ \\
Dia. of member 2 & $12.00 \mathrm{~mm}$ & $4.05 \mathrm{~mm}$ \\
Dia. of member 3 & $18.00 \mathrm{~mm}$ & $4.05 \mathrm{~mm}$ \\
\hline \multicolumn{2}{|c|}{ Minimized volume in cubic mm. $=4678.3$} \\
\hline
\end{tabular}

Several researchers have used the random search technique. particularly for solving problems in kinematics. The combinatorial heuristic random search was used by Lee and Freundstein [12] for the analysis of linkages. An approach, to design of gear boxes using a random search technique has been reported by cleghorn, Fenton and Fu [4] .

\section{1 HELICAL GEAR OPTIMIZATION}

The problem of optimal design of helical gears has been dealt with by only one group of researchers [Jog and Pande, 10]. In their optimum design process, they had linearized their problem and implemented the optimization sequence using the simplex method. This method does a good job 
only as long as the constraints are linear. It would only produce an approximate solution, especially when the problem assumes larger dimensions and the number of constraints increase. Also the simplex method is starting solution dependent, and the initial design should itself lie within the feasible region. Vanderplaats [19] has reported the use of a nonlinear optimization strategy for the design of helical gears but no documentation is available for this work. Work on optimal design for spur gears has been reported by several researchers (Carroll and Johnson [2, 3] and Zarak [20]).

In the current project the objective is to reduce the weight of a pair of steel helical gears, subject to the constraints of bending and contact stresses. The standard gear form with $20^{\circ}$ pressure angle is considered.

\subsection{PROBLEM OF HELICAL GEAR DESIGN}

\section{objective}

The objective of the problem is to minimize the weight of a pair of helical gears. The volume of the gear is approximated to the volume of a cylinder with the pitch diameter as the outer diameter. The objective function is,

$$
\mathrm{W}=\mathrm{V} \rho
$$

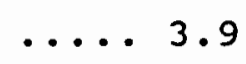

and,

$$
V=\frac{\pi d_{p}^{2} f}{4}
$$

substituting for $d_{p}$ with, 


$$
\begin{gathered}
a_{p}=\frac{m_{n} N}{\cos \psi} \\
V=\frac{\pi\left(\frac{m_{n} N}{\cos \psi}\right)^{2} f}{4}
\end{gathered}
$$

where,

$$
\begin{aligned}
& \mathrm{w}=\text { Weight in } \mathrm{kg} \\
& \mathrm{v}=\text { Volume in } \mathrm{mm}^{3} \\
& \mathrm{~d}_{\mathrm{p}}=\text { Pitch diameter of pinion in mm } \\
& \mathrm{f}=\text { Facewidth in } \mathrm{mm} \\
& \mathrm{m}_{\mathrm{n}}=\text { Normal module in } \mathrm{mm} \\
& \mathrm{N}=\text { Number of teeth on pinion } \\
& \Psi \quad=\text { Helix angle in degrees } \\
& \rho \quad=\text { Density of material in } \mathrm{kg} / \mathrm{mm}^{3}
\end{aligned}
$$

\section{Constraints}

The contact stress and the bending stress are modelled as constraints for the problem, although as many constraints as necessary can be included in the problem.

contact stress. The contact stress due to loading is determined using the AGMA equation [AGMA,21]

$$
s_{c} \leq C_{p} \sqrt{\frac{W_{t} C_{a} C_{s} C_{m} C_{t}}{C_{v} d f I}}
$$

Bending stress. The bending stress is also calculated as,

$$
s_{t} \leq \frac{W_{t} K_{a} K_{s} K_{m} K_{b}}{K_{v} f m J}
$$


using the AGMA equation [AGMA, 21].

Appendix A details the steps required in the determination of the different factors used in the calculation of $S_{c}$ and $s_{t}$.

\section{Design Variables}

The design variables in this problem are

$$
\begin{aligned}
& \text { 1) module, } \\
& \text { 2) helix angle, } \\
& \text { 3) number of teeth on pinion and } \\
& \text { 4) facewidth. }
\end{aligned}
$$

The boundary conditions on these variables are determined based on the operating condition of the gear.

In order to accomplish the design process the inputs indicated in Appendix A are received from the designer.

\subsection{DESIGN EXAMPLE}

The random search algorithm was tested with a problem from Shigley and Mitchell [16]. The problem is presented below.

$$
\begin{array}{ll}
\text { Transmitted Power } & =74.6 \mathrm{~kW} \\
\text { Pinion Speed } & =1120 \mathrm{rpm} \\
\text { Gear Ratio } & =4 \\
\text { Pressure Angle } & =20^{\circ} \\
\text { Permissible Bending Strength } & =155 \mathrm{MPa} \\
\text { Permissible Contact Strength } & =530 \mathrm{MPa}
\end{array}
$$

The strength values are read from the tables and correction factors applied to it, to result in 
values shown above.

Maximum permissible Helix angle $=35^{\circ}$

\subsection{RESULT AND DISCUSSION}

The results are tabulated in Table IV. The results show that all the four design variables have changed significantly. The graphs of all four variables seem to be similar, which is because of the uniform change in the value of the variables. The results are compared with those from a gradient based approach.

The gradient based approach failed to give a solution within 100 iterations. Even with increased number of iterations the solution was not as good as the one achieved with the random search. The values from random search and gradient based approach are shown in Table IV.

As a side note on the use of an effective interactive environment for interactive optimization, as could be seen in the example, from the graphs presented, the facewidth could be held at the constant value of about $34.3 \mathrm{~mm}$ after the $56^{\text {th }}$ iteration and allowing the other variables to change. This way the process of optimization could be speeded up and could be efficient with the use of human intelligence. The graphs generated by the program, are shown in figure 8 . Figure 9 shows the behavior of the design variables during each epoch. In this case the graphs are plotted for epoch number 7 .

In the present problem, optimization is done with the 
constraints of bending and contact. However any number of constraints could be added to the system. The program also generates a complete set of design details, required for the manufacturing process. These data are shown in Table $\mathrm{V}$. 


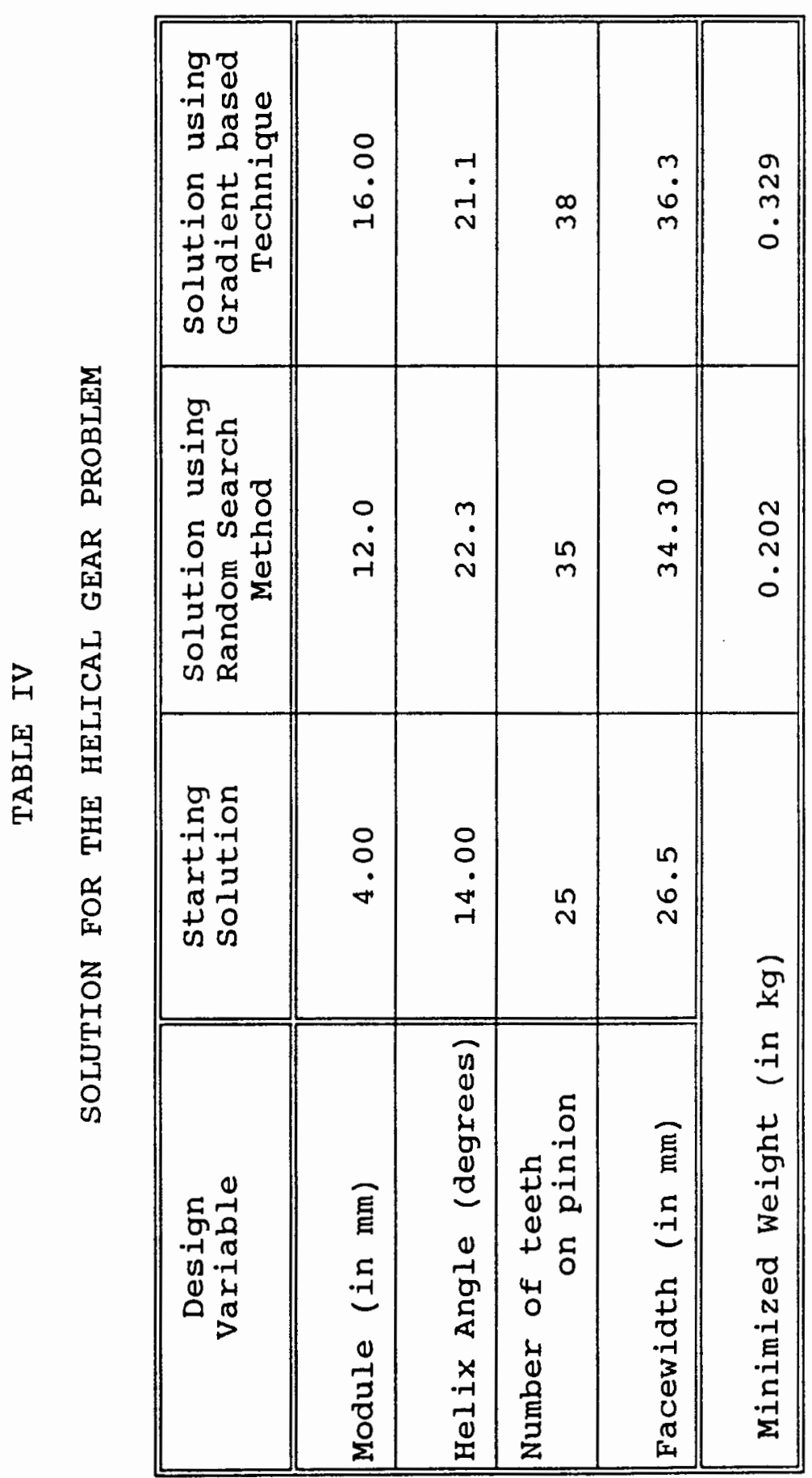




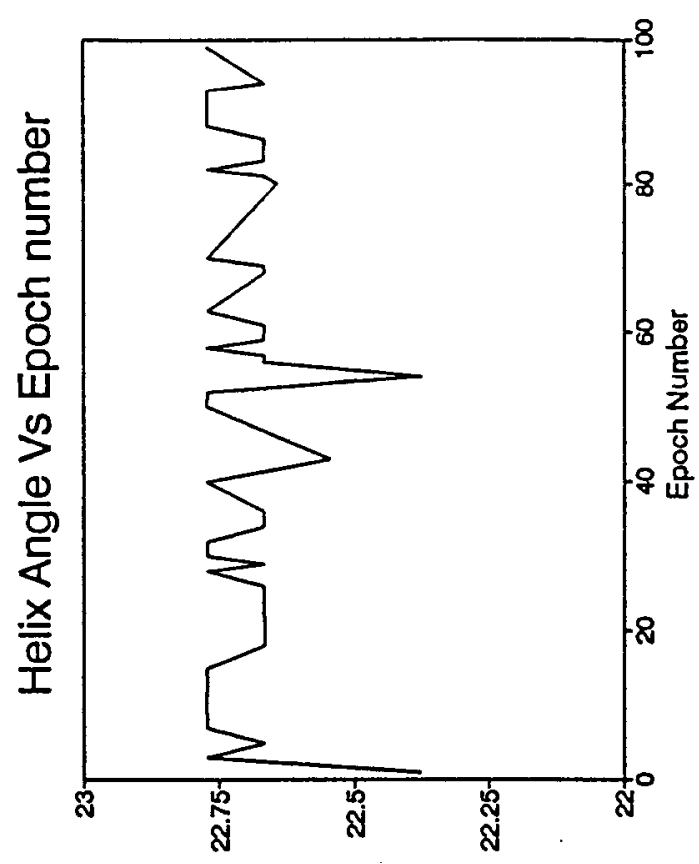

(soed6ep u1) e|6us xpleH
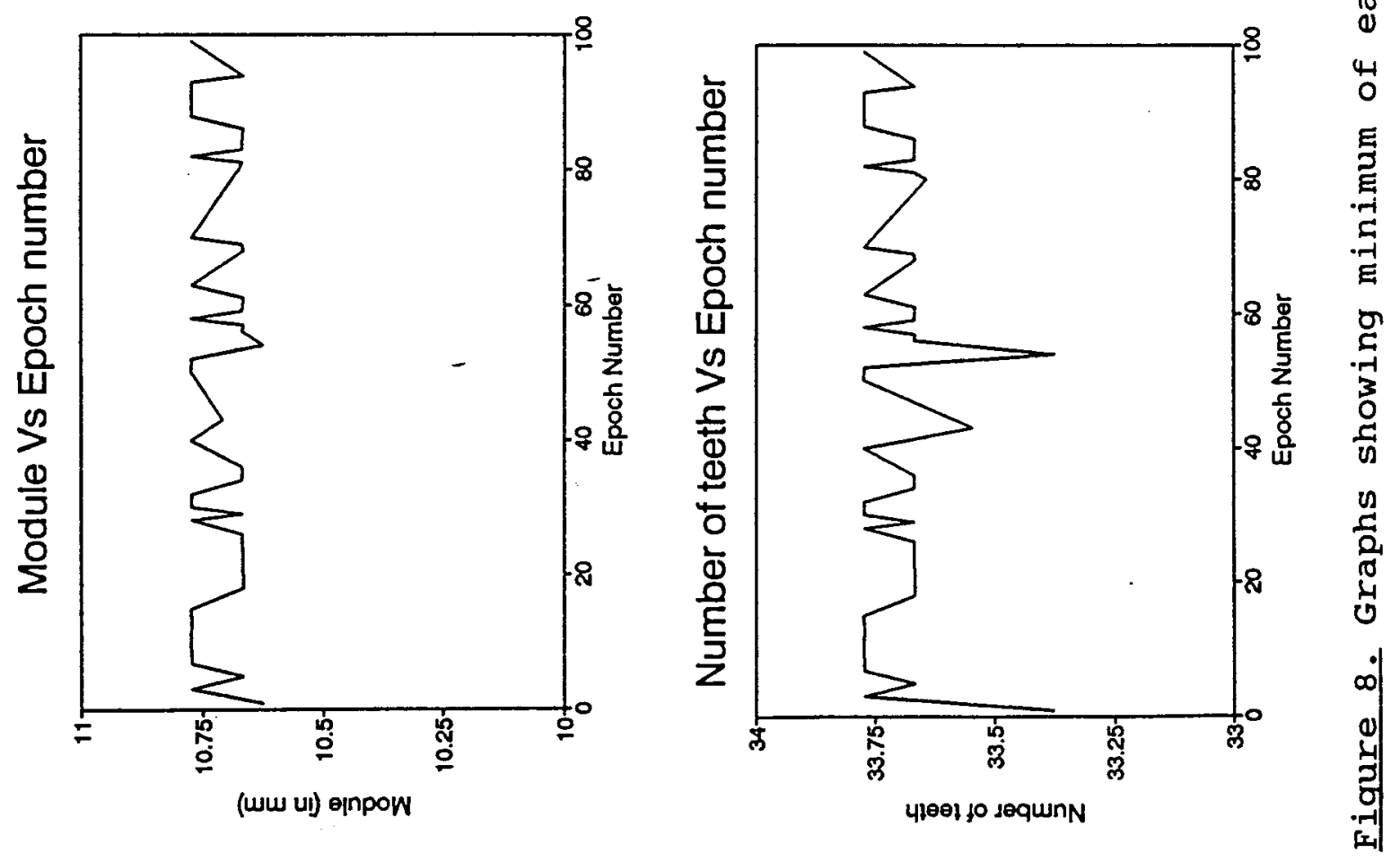

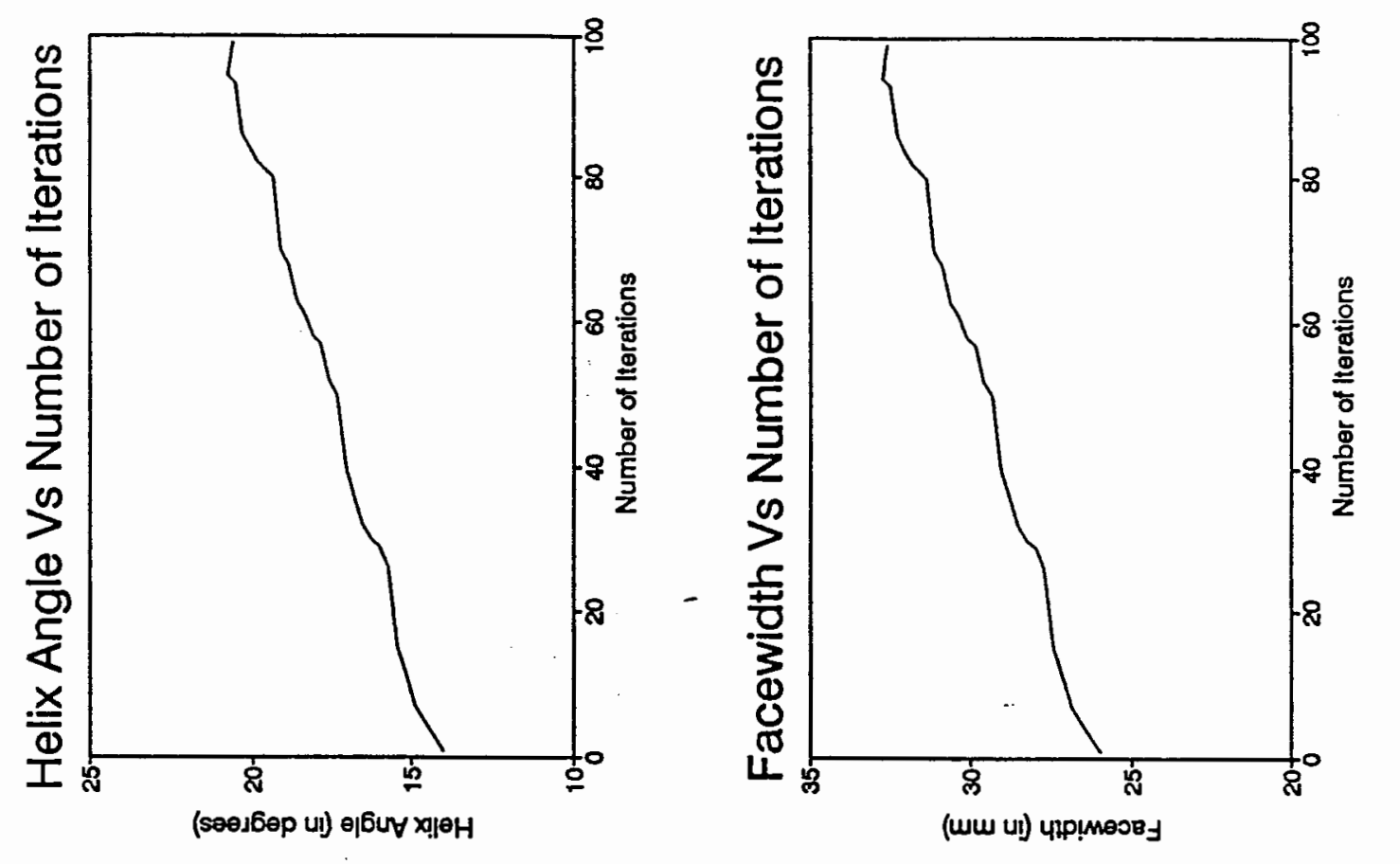

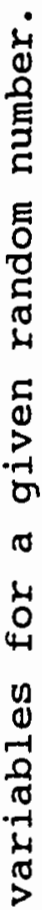
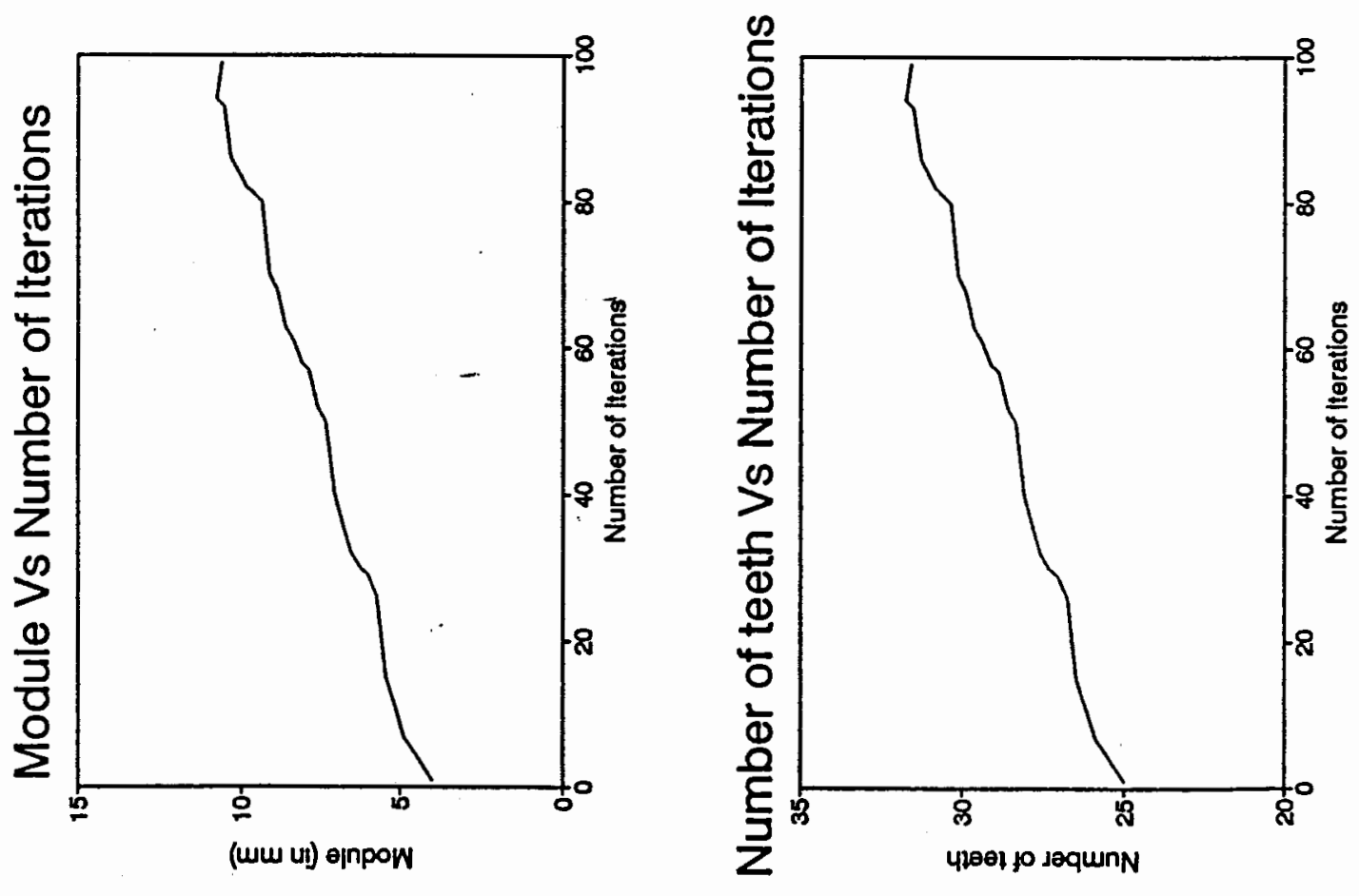

넝

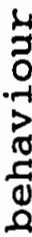

દ్

4 
TABLE V

GEAR DESIGN DETAILS FOR MANUFACTURING

$$
\begin{aligned}
& \text { Normal module } \quad=2.0 \mathrm{~mm} \\
& \text { Traverse module } \quad=2.1 \mathrm{~mm} \\
& \text { Normal pressure angle }=20 \text { degrees } \\
& \text { Traverse pressure angle }=0.4 \text { degrees } \\
& \text { Helix angle }=14.0 \text { degrees } \\
& \text { Number of teeth (pinion) }=26 \\
& \text { Pitch diameter (pinion) }=51.0 \mathrm{~mm} \\
& \text { Base diameter (pinion) }=47.0 \mathrm{~mm} \\
& \text { Helix lead } \quad=12.7 \mathrm{~mm} \\
& \text { Major diameter }(\text { pinion) }=56.0 \mathrm{~mm} \\
& \text { Root diameter (pinion) }=47.0 \mathrm{~mm} \\
& \text { Addendum (pinion) }=2.5 \mathrm{~mm} \\
& \text { Facewidth } \quad=26.0 \mathrm{~mm} \\
& \text { Quality number } \quad=10 \\
& \text { Volume } \quad(\text { pinion })=53054.46 \mathrm{~mm}^{3} \\
& \text { Weight } \quad(\text { pinion })=2.02 e-001 \mathrm{~kg} \\
& \text { Material (pinion) }=\text { steel Through hardened } \\
& \text { tempered (AGMA Class 5) } \\
& \text { Number of teeth (gear) }=102 \\
& \text { Material (gear) = Steel Carburised \& case } \\
& \text { hardened } \\
& \text { Weight (gear) }=8.24 \mathrm{e}-001 \mathrm{~kg}
\end{aligned}
$$


CHAPTER IV

\section{CONCLUSION}

This project was intended to show the use of optimization techniques for the design of machine elements. The focus of this project was on the use of non-linear constraints in optimization without linearizing them, which was achieved by using a robust random search algorithm. The helical gear design problem which has complex constraints has been satisfactorily optimized using the random search method. With increase in computational power it is hoped that faster and more accurate solutions could be achieved. The results of the random search method have been compared to the gradient based approach and the results are better for this problem.

Finally it is the objective of this work to set a trend in optimization, as it is a very vital component of design. A new dimension to optimization - user interactiveness, has been incorporated to a limited extent. A possible extension of this project will be to develop optimization strategies specifically for the domain of design of other machine elements like springs and fasteners and also for the optimization of structure and shape of machineries, with a better implementation of user interactiveness. 


\section{REFERENCES}

[1] Arora, J.S., "Introduction to Optimum Design", McGraw Hill Publishing, 1989.

[2] Carroll, R.K and Johnson, G.E., "Optimal Design of Compact Spur Gear Sets", ASME Journal of Mechanisms, Transmissions and Automation in Design, Vol. 106, p95102,1984 .

[3] Carroll, R.K. and Johnson, G.E., "Dimensionless solution to the Optimal Design of Spur Gear Sets", ASME Journal of Mechanisms, Transmissions and Automation in Design, p290296, Vol. 111, 1989.

[4] Cleghorn, W.L., Fenton, R.G. and Fu, J.-F., "A General Method for optimum Design of Gear Boxes Through NonLinear Programming", Proceedings of the 16th Design Automation Conference, Chicago, 1989.

[5] Drago, R.J., "Fundamentals of Gear Design", Butterworth Publishers, 1988.

[6] Dudley, D.W., "Gear Handbook", McGraw Hill Publishing, 1962 .

[7] Dudley, D.W., "Handbook of Practical Gear Design", McGraw Hill publishing, 1984.

[8] Golik, Tim, "Optimization of a Three Bar Truss using Random Search Technique", Class Project, Portland state University, 1990.

[9] Jacoby, S.L.S., Kowalik, J.S. and Pizzo, J.T., "Iterative methods for Non-Linear optimization Problems", PrenticeHall Publications, 1972.

[10] Jog, C.S and Pande, S.S, "Computer Aided Design of Compact Helical Gear Sets", ASME Journal of Mechanisms, Transmissions and Automation in Design, Vol. 111, p285289,1989 .

[11] Lee, T.W and Freundstein, F., "Heuristic Combinatorial optimization in the Kinematic Design of Mechanisms: Part I", Journal of Engineering for Industry, Transaction of ASME, p1277-1280, 1976. 
[12] Lee, T.W and Freundstein, F., "Heuristic Combinatorial optimization in the Kinematic Design of Mechanisms: Part II", Journal of Engineering for Industry, Transactions of ASME, p1281-1284, 1976 .

[13] Lipp, R., "Avoiding Tooth Interference in Gears", Machine Design, p122-124, Vol. 54, No. 1, 1982

[14] Reklatis, G.V., Ravindran, A. and Ragsdell, K.M., "Engineering optimization: Methods and Application", John wiley Publishing, 1983.

[15] Schumer, M.A and Steiglitz, K., "Adaptive Step Size Random Search", IEEE Transactions on Automatic control, Vol. 13, p270-276, 1968.

[16] Shigley, J.E and Mischke, C.R, "Mechanical Engineering Design", McGraw Hill Publishing, 1989.

[17] Shigley, J.E and Mischke, C.R, "Handbook of Machine Design", McGraw Hill Publishing, 1989.

[18] Vanderplaats, G.N., "Numerical optimization Techniques for Engineering Design: with Applications", McGraw Hill Publishing, 1984 .

[19] Vanderplaats, G.N., Xiang Chen and Ning-tian zhang, "Gear optimization", NASA Contractor Report 4201, NASA Scientific and Technical Division, 1988.

[20] Zarak, C., "Optimal Gear Design", Ph.D Dissertation, Department of Mechanical Engineering, Vanderbilt University, 1985 .

[21] "AGMA standard for Rating the Pitting Resistance and Bending strength of spur and Helical Involute Gear Teeth", AGMA 2001-B88 American Gear Manufacturers Association, Arlington, 1989.

[22] "AGMA Standard for Geometry Factors for determining the Pitting Resistance and Bending strength of Spur Helical and Herringbone Gear Teeth", AGMA 908 - B89, American Gear Manufacturers Association, Arlington, 1989.

[23] "AGMA Gear Handbook", Volume 1, AGMA 390.03, American Gear Manufacturers Association, Arlington, 1980.

[24] "IMSL- Math Library", IMSL, Houston, Texas, 1987. 
[25] "Numerical Methods for Non-Linear optimization", Proceedings of the conference sponsored by Science Research Council, University of Dundee, Scotland, edited by Lootsma, F.A., Academic Press, 1972 . 
APPENDIX A

HELICAL GEAR DESIGN PROCEDURE 
APPENDIX A

HELICAL GEAR DESIGN PROCEDURE

The following parameters are required as input for the design process.

1) Power to be transmitted

2) Speed of pinion in rpm

3) Gear Ratio

4) Maximum Helix Angle

5) Permissible center distance and

6) Area of application of the gear pair.

All the parameters are to be entered in the SI units.

The application of the gear is also received as input. A set of data representative of the areas is collected and is stored as a data file. Table VI shows the listing of this data.

The following process is used for selecting the upper and lower bound for each of the variables. These values and tables are extracted from the AGMA standards and other texts.

1. Select the AGMA number and the value of application factors, $\mathrm{c}_{\mathrm{a}}$ and $\mathrm{K}_{\mathrm{a}}$ using the area of application [Table VII]

2. Based on the maximum helix angle select the minimum number of teeth on the pinion [Table VIII]. 
3. Using the AGMA number the maximum permissible module for the pair of gears is determined. Usually the highest module is 48 .

4. Based on the minimum number of teeth, select the minimum hardness of pinion [Table IX].

5. Select a value for ' $K$ '-factor based on the application [Table $\mathrm{X}]$. Using the same table, also select the hardness for the gear material.

6. Based on hardness of pinion and gear, select a steel material. Also select the corresponding Upper and lower limits of contact and bending stresses [Table XI, XII]. This completes the selection phase, where the upper and lower bounds on each of the variables are determined. The next phase of design is optimization, where the constraints are to be satisfied.

The constraints are,

$$
\begin{gathered}
S_{c}=C_{p} \sqrt{\frac{W_{t} C_{a} C_{s} C_{m} C_{f}}{C_{v} d f I}} \\
S_{t}=\frac{W_{t} K_{a} K_{s} K_{m} K_{b}}{K_{v} f m J}
\end{gathered}
$$

where,

$$
d=\frac{2 C}{m_{g}+1}
$$

and,

$\mathrm{S}_{\mathrm{c}}=$ contact stress in $\mathrm{MPa}$

$\mathrm{S}_{\mathrm{t}}=$ bending stress in $\mathrm{MPa}$

$c_{p}=$ elastic coefficient in $[\mathrm{MPa}]^{\frac{1}{2}}$ 
$\mathrm{W}_{\mathrm{t}}$ = transmitted load in $\mathrm{N}$

$\mathrm{C}_{\mathrm{a}}$ = application factor for pitting

$\mathrm{C}_{\mathrm{s}}=$ size factor for pitting

$C_{m}=$ load distribution factor for pitting

$\mathrm{C}_{\mathrm{f}}=$ surface condition factor for pitting

$C_{v}=$ dynamic factor for pitting resistance

$\mathrm{f}=$ net face width of narrowest member in $\mathrm{mm}$

$I=$ geometry factor for pitting

$\mathrm{d}=$ operating pinion pitch diameter in $\mathrm{mm}$

$C=$ operating center distance in $\mathrm{mm}$

$\mathrm{m}_{\mathrm{g}}$ = gear ratio (greater than 1.0 )

$\mathrm{K}_{\mathrm{a}} \quad$ application factor for bending

$\mathrm{K}_{\mathrm{b}}=$ rim thickness factor

$\mathrm{K}_{\mathrm{s}} \quad=$ size factor for bending

$K_{m}=$ load distribution factor for bending

$\mathrm{K}_{\mathrm{v}}$ = dynamic factor for bending

$\mathrm{J} \quad$ = geometry factor for bending

$\mathrm{m}=$ metric module in $\mathrm{mm}$

and

$$
I=\frac{C_{c} C_{x} C_{\psi}}{m_{n}}
$$

where,

$c_{c}=$ curvature factor at pitch line

$c_{x}=$ contact height factor

$c_{\psi}=$ helical overlap

where, 


$$
J=\frac{Y C_{\psi}}{K_{P} m_{n}}
$$

$$
\begin{aligned}
& \mathrm{Y}=\text { tooth form factor } \\
& \mathrm{K}_{\mathrm{f}}=\text { stress concentration factor }
\end{aligned}
$$

The transmitted load is determined as,

$$
W_{t}=\frac{1.91 \times 10^{7} \times P}{n_{p} d}
$$

where,

$$
\begin{aligned}
& \mathrm{P}=\text { power to be transmitted in } \mathrm{kW} \\
& \mathrm{n}_{\mathrm{p}}=\text { speed of pinion in rpm } \\
& \text { The pitch line velocity is, }
\end{aligned}
$$

$$
v_{t}=\frac{\pi n_{p} d}{60000}
$$

where,

$$
\begin{aligned}
\mathrm{vt}= & \text { pitch line velocity at operating pitch diameter in } \\
& \mathrm{m} / \mathrm{s}
\end{aligned}
$$

The dynamic factors $K_{v}$ and $C_{v}$ are determined using the equation given below

$$
C_{v}=K_{\mathrm{v}}=\left(\frac{A}{A+\sqrt{200 v_{t}}}\right)^{B}
$$

where,

$$
\mathrm{A}=50+56(1.0-\mathrm{B})
$$

and

$$
B=\frac{\left(12-Q_{V}\right)^{0.667}}{4}
$$


$Q_{\mathrm{v}}=$ =accuracy level number determined from application, refer Table VII.

The application factors $c_{a}$ and $K_{a}$ are obtained during the selection process itself, depending on the application [Table XIII] •

The elastic coefficient is calculated using the formula,

$$
C_{p}=\sqrt{\frac{1.0}{\pi\left[\frac{\left(1.0-\mu_{p}{ }^{2}\right)}{E_{p}}+\frac{\left(1.0-\mu_{g}{ }^{2}\right)}{E_{g}}\right]}}
$$

where,

$c_{p}=$ elastic coefficient in $\mathrm{MPa}^{\frac{1}{2}}$

$\mu_{p}, \mu_{g}=$ Poisson's ratio for pinion and gear respectively

$E_{p}, E_{g}=$ Modulus of elasticity of pinion and gear respectively.

since only steel pairs are considered, $\mathrm{Cp}=191 \mathrm{MPa}^{\frac{1}{2}}$. Surface condition factor is unknown and hence a value of 1 is assumed.

For further information see AGMA standards [21,22]. 


\section{APPENDIX B}

RANDOM SEARCH METHOD AS A USER CALLABLE PROGRAM 


\section{APPENDIX B}

\section{RANDOM SEARCH METHOD AS A USER CALLABLE PROGRAM}

The Random Search method can be used as a user callable program. A listing of the non-linear problem discussed in Chapter 3, eq 3.1 through 3.4 are presented. The user has to define the variables global to the function. Any number of design variables may be used in the problem.

The Random search algorithm is coded in Microsoft $C$, version 6.00. All the information below will hold good for Microsoft $C$ compilers.

\section{For The Objective function}

The objective function has to be stored as OBJECTIV.C objectiv(y,cfval)

float $y[5], *$ cfval;

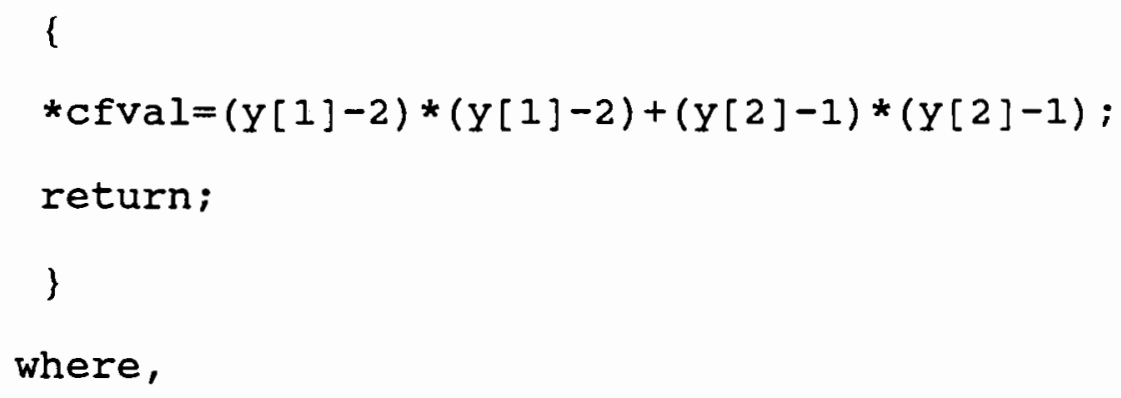

where,

- objectiv is the calling name for objective function

- $y[5]$ are the variables representing the design variables in the problem and

- cfval is the value of the objective function. 
Note: The use of ' $*$ ' before cfval is essential in the $C$ programming environment.

\section{For The constraints}

The constraints should be stored as CONSTRNT.C constrnt $(y)$

float $Y[5]$;

$$
\begin{aligned}
& \operatorname{cg}[0]=y[1]-2 * y[2]+1 ; \\
& \operatorname{cg}[1]=-(y[1] * y[1]) / 4-(y[2] * y[2])+1 ;
\end{aligned}
$$

return;

$$
\text { \} }
$$

where,

- constrnt is the calling name for the constraint set

- y[5] are the design variables and

- $\operatorname{cg}[0], \operatorname{cg}[1]$ are the constraint equations.

Note: The user can add any number of constraints to the problem. The number of constraints used in the problem can be accommodated by a user input to a query in the main program. The user may also wish to add design details here.

\section{How to link and run?}

\section{Linking}

Once the functions are defined, they are compiled using the following format, preferably adhering to the upper and lower 
case alphabets as shown below.

$$
\text { cl /c random.c }
$$

The program is then linked as,

$$
\text { link random/ST: } 4112
$$

where, /ST:4112 sets the stack size to be used to 4112 bytes.

\section{Input and output}

The user has to input the following information.

1) Number of design variables, ' $n$ ',

2) Starting solution for ' $n$ ' design variables,

3) Upper and lower bound for the design variables,

4) Number of iterations to be performed and

5) The number of constraints to be used.

The program would produce the final optimized value as the solution. The output contains the minimized function value and the corresponding design variables. 
APPENDIX C

TABLES USED IN HELICAL GEAR DESIGN 
APPENDIX C

TABLES USED IN HELICAL GEAR DESIGN

TABLE VI

A BROAD CLASSIFICATION OF APPLICATIONS

\begin{tabular}{|l|l|}
\hline Aerospace & $\begin{array}{l}\text { 1) Control and Instrumentation gears } \\
\text { 2) Engine and Transmission gears } \\
\text { 3) Accesories }\end{array}$ \\
\hline $\begin{array}{l}\text { Industrial } \\
\text { and } \\
\text { Machine Tool }\end{array}$ & $\begin{array}{l}\text { 4) Transmission (powered) gears } \\
\text { 6) Precision indexing and positioning }\end{array}$ \\
\hline Turbine and & 7) Vehicle gears (in transmission) \\
\hline Generator & 9) Accesories \\
\hline Others & 10) Agricultural accesories \\
& 11) Low precision machines \\
\hline
\end{tabular}




\section{APPLICATION AND SUGGESTED QUALITY NUMBERS FOR SPUR, HELICAL, HERRINGBONE, BEVEL AND HYPOID GEARS, RACKS AND WORM GEARING}

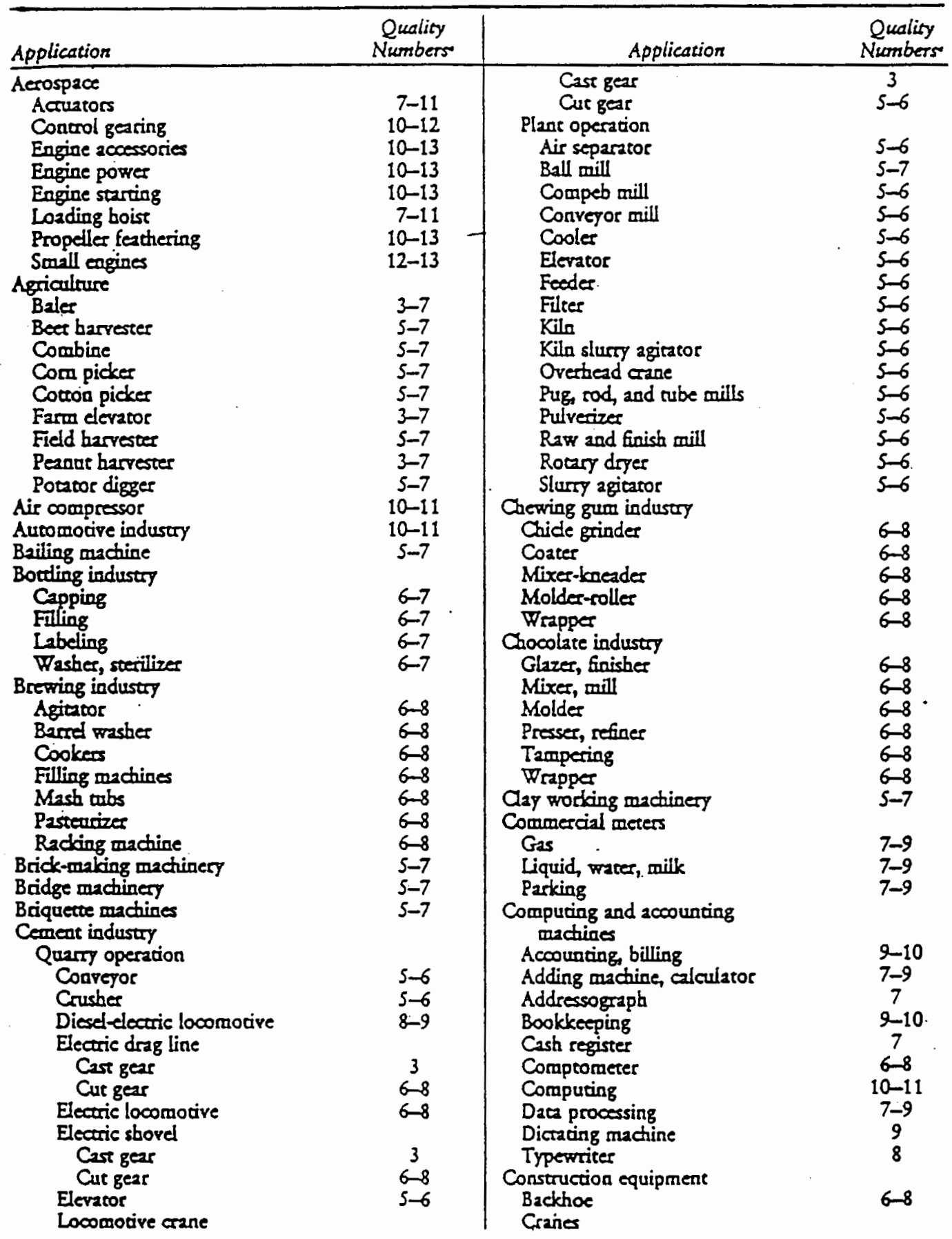


TABLE VII

APPIICATION AND SUGGESTED QUALITY NUMBERS FOR
SPUR, HELICAL, HERRINGBONE, BEVEL AND HYPOID
GEARS, RACKS AND WORM GEARING
(continued)

\begin{tabular}{|c|c|c|c|}
\hline Application & $\begin{array}{l}\text { Quality } \\
\text { Numbers }\end{array}$ & Application & $\begin{array}{l}\text { Quality } \\
\text { Numibers }\end{array}$ \\
\hline $\begin{array}{l}\text { Open gearing } \\
\text { Enclosed gearing }\end{array}$ & $\begin{array}{l}3-6 \\
6-8\end{array}$ & \multirow{19}{*}{\multicolumn{2}{|c|}{$\begin{array}{l}\text { Electronic instrument control } \\
\text { and guidance systems } \\
\text { Accelerometer } \\
\text { Airborme teraperature recorder } \\
\text { Aircraft instrument } \\
\text { Altimeter-stabilizer } \\
\text { Analog compurer } \\
\text { Anreana assembly } \\
\text { Antiaircaft detector } \\
\text { Automatic pilor } \\
\text { Digial computer } \\
\text { Gun-dare computer } \\
\text { Gyro caging mechanism } \\
\text { Gyroscope-omputer } \\
\text { Pressure transducer } \\
\text { Radar, sonar, runer } \\
\text { Recorder, telemeter } \\
\text { Servo system component } \\
\text { Sound derecor } \\
\text { Transmitter, receiver } \\
\text { Engines }\end{array}$}} \\
\hline Ditch digger & $3-8$ & & \\
\hline Transmission & $6-8$ & & \\
\hline Drag line & $5-8$ & & \\
\hline Dumpster & $6-8$ & & \\
\hline Paver & & & \\
\hline Loader & 3 & & \\
\hline Transmission & 8 & & \\
\hline Mixer & $3-5$ & & \\
\hline Swing gear & $3-5$ & & \\
\hline Mixing bueket & $\begin{array}{l}3 \\
8\end{array}$ & & \\
\hline $\begin{array}{l}\text { Shaker } \\
\text { Shovels }\end{array}$ & 8 & & \\
\hline Open gearing & $3-6$ & & \\
\hline Endosed gearing & $6-8$ & & \\
\hline Stationary mixer & & & \\
\hline Transmission & 8 & & \\
\hline Drum gears & & & \\
\hline Stone crusher & & & \\
\hline Transmission & 8 & & \\
\hline Coaveyor & 6 & \multirow{2}{*}{\multicolumn{2}{|c|}{$\begin{array}{l}\text { Diesel, semidiesch, and internal } \\
\text { combustion engine }\end{array}$}} \\
\hline Truck mixer & & & \\
\hline Transfer case & 9 & 20 essories & $10-12$ \\
\hline Drum gears & $3-5$ & Supercharger & $10-12$ \\
\hline Cranes & & Timing gearings & $\begin{array}{r}10-12 \\
8-10\end{array}$ \\
\hline Boom boist & $5-6$ & Transmission & $8-10$ \\
\hline Gantry & $5-6$ & Farm equipmear & \\
\hline Load boist & $\begin{array}{l}5-7 \\
s-6\end{array}$ & Milking machine & $\begin{array}{l}6-8 \\
8-10\end{array}$ \\
\hline $\begin{array}{l}\text { Overhead } \\
\text { Ship }\end{array}$ & $\begin{array}{l}5-6 \\
5-7\end{array}$ & Separator & $\begin{array}{l}8-10 \\
4-6\end{array}$ \\
\hline $\begin{array}{l}\text { Ship } \\
\text { Crusters }\end{array}$ & & $\begin{array}{l}\text { Swecper } \\
\text { Flour mill indusery }\end{array}$ & \\
\hline lo, feed & $6-8$ & Bleacher & $7-8$ \\
\hline Pormble and stationary & $6-8$ & Grain deaner & $7-8$ \\
\hline Rock, ore, cosl & $6-8$ & Grinder & $7-8$ \\
\hline Dairy industry & & Hulling & $7-8$ \\
\hline Bortle washer & $6-7$ & Milling, scouring & $7-8$ \\
\hline Homogenizer & $7-9$ & Polisher & $7-8$ \\
\hline Separator & $7-9$ & Separator & $7-8$ \\
\hline Dams and looks & & Foundry industry & \\
\hline Taincer gates & $5-7$ & Conveyor & $5-6$ \\
\hline Dishwasher & & Elevator & $s-6$ \\
\hline Commercial & $5-7$ & Ladle & $5-6$ \\
\hline Discrillery industry & & Molding machine & $5-6$ \\
\hline Agitator & $5-7$ & Overhead cranes & $5-6$ \\
\hline Botde filler & $5-7$ & Sand mixer & $5-6$ \\
\hline Conveyor, elevator & $6-7$ & Sand slinger & $5-6$ \\
\hline Geain pulverizer & $6-8$ & Tumbling aill & $5-6$ \\
\hline Mash tub & $5-7$ & Horne appliances & \\
\hline Mixer & $5-7$ & Blender & $6-8$ \\
\hline Yezst tub & $5-7$ & Mixer & $\begin{array}{l}7-9 \\
8-10\end{array}$ \\
\hline Electric fumace & & Timer & $8-10$ \\
\hline
\end{tabular}


TABLE VII

\begin{abstract}
APPIICATION AND SUGGESTED QUALITY NUMBERS FOR SPUR, HELICAI, HERRINGBONE, BEVEL AND HYPOID GEARS, RACKS AND WORM GEARING (continued)
\end{abstract}

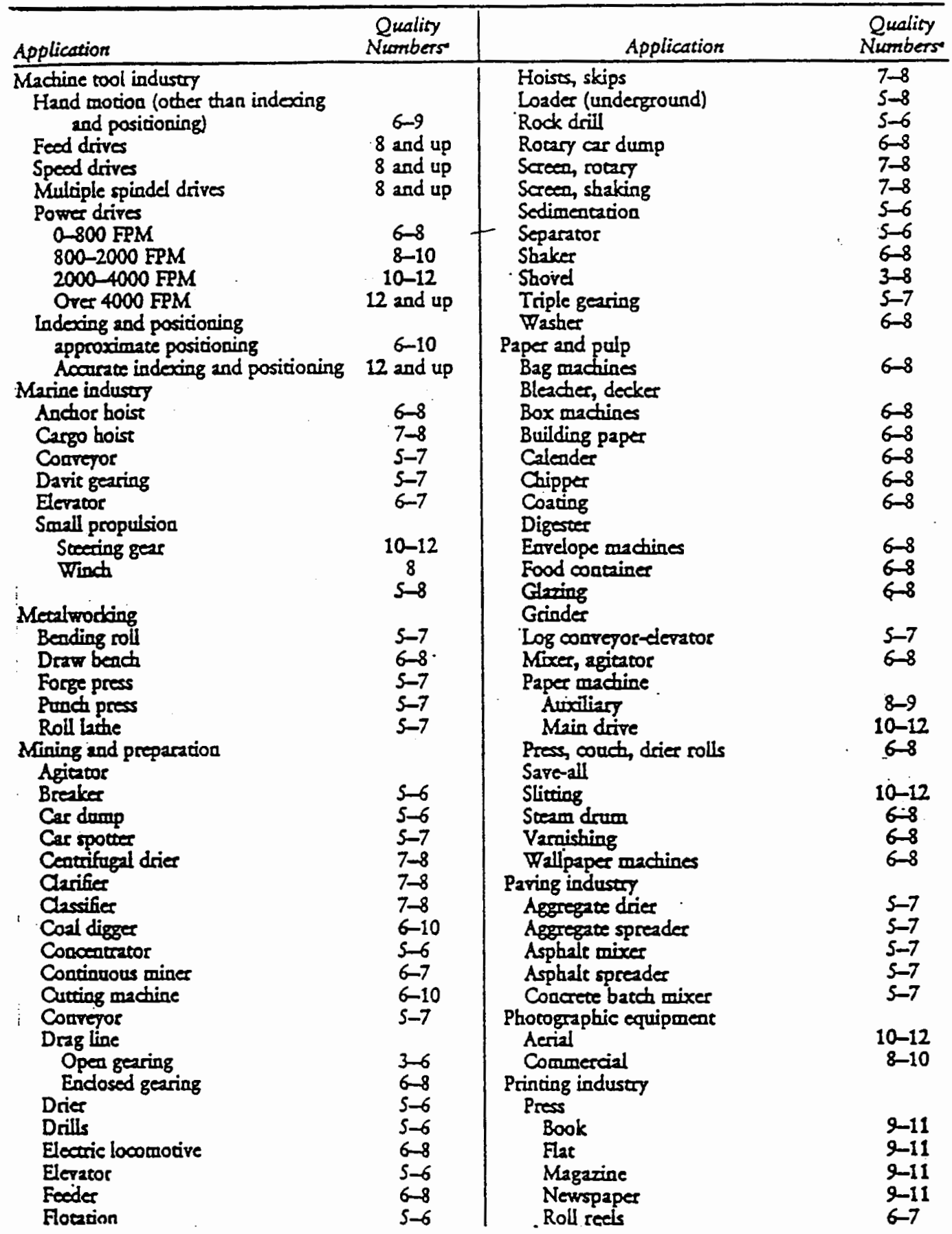


TABLE VII

\begin{abstract}
APPLICATION AND SUGGESTED QUALITY NUMBERS FOR SPUR, HELICAL, HERRINGBONE, BEVEL AND HYPOID GEARS, RACKS AND WORM GEARING

(continued)
\end{abstract}

\begin{tabular}{|c|c|c|c|}
\hline Application & $\begin{array}{l}\text { Quality } \\
\text { Numbers }\end{array}$ & Application & $\begin{array}{l}\text { Quality } \\
\text { Numbers }\end{array}$ \\
\hline 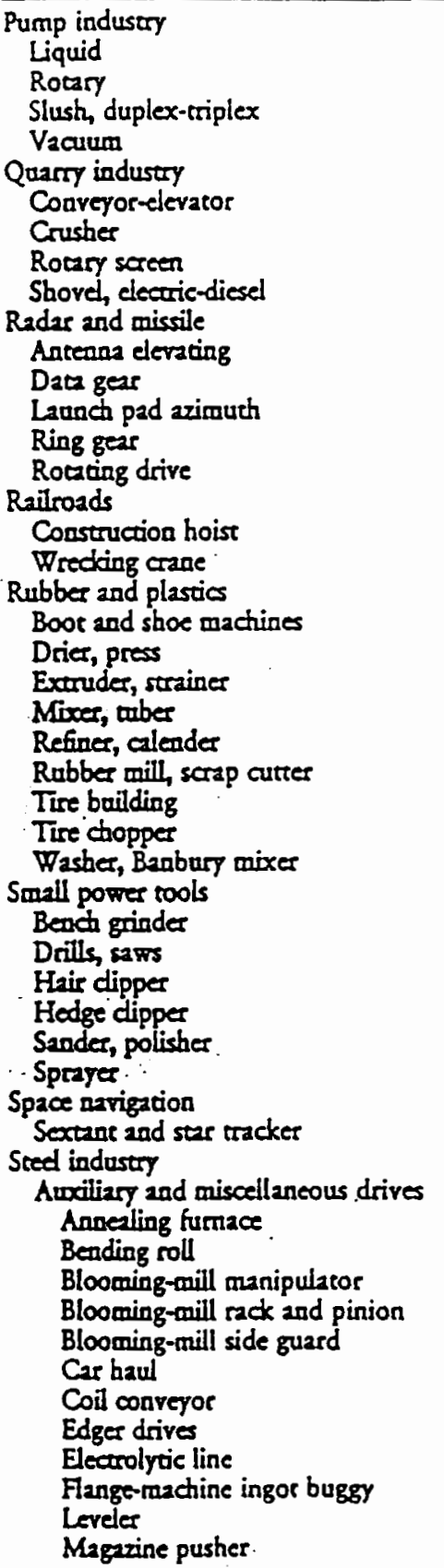 & $\begin{array}{c}6-7 \\
5-7 \\
7-8 \\
7-8 \\
8-10 \\
10-12 \\
8 \\
9-12 \\
10-12 \\
5-7 \\
6-8 \\
6-8 \\
6-8 \\
6-8 \\
6-8 \\
5-7 \\
5-7 \\
6-8 \\
5-7 \\
5-7 \\
6-8 \\
7-9 \\
7-9 \\
7-9 \\
8-10 \\
6-8\end{array}$ & 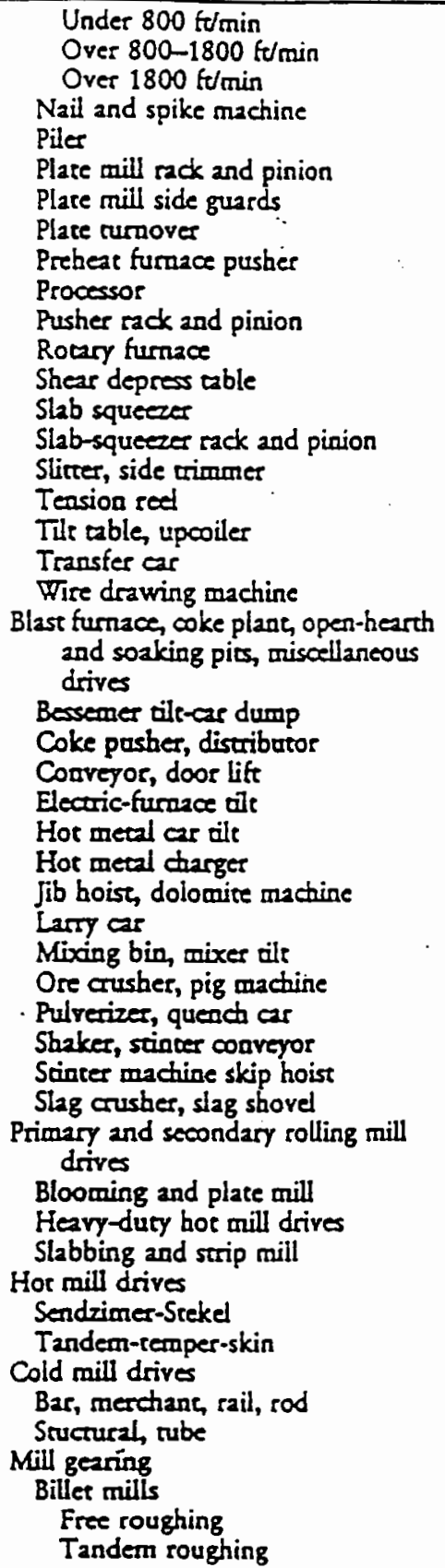 & $\begin{array}{c}5-6 \\
b-7 \\
8 \\
s-6 \\
5-6 \\
s-6 \\
5-6 \\
5-6 \\
5-6 \\
6-7 \\
5-6 \\
5-6 \\
5-6 \\
5-6 \\
s-6 \\
6-7 \\
6-7 \\
s-6 \\
5-6 \\
6-7\end{array}$ \\
\hline
\end{tabular}

Source: [AGMA 390.03, 23] 
TABLE VII

\begin{abstract}
APPLICATION AND SUGGESTED QUALITY NUMBERS FOR SPUR, HELICAL, HERRINGBONE, BEVEL AND HYPOID GEARS, RACKS AND WORM GEARING (continued)
\end{abstract}

\begin{tabular}{|c|c|c|c|}
\hline Applicasion & $\begin{array}{l}\text { Quality } \\
\text { Numbers }\end{array}$ & Application & $\begin{array}{l}\text { Qualits } \\
\text { Number. }\end{array}$ \\
\hline 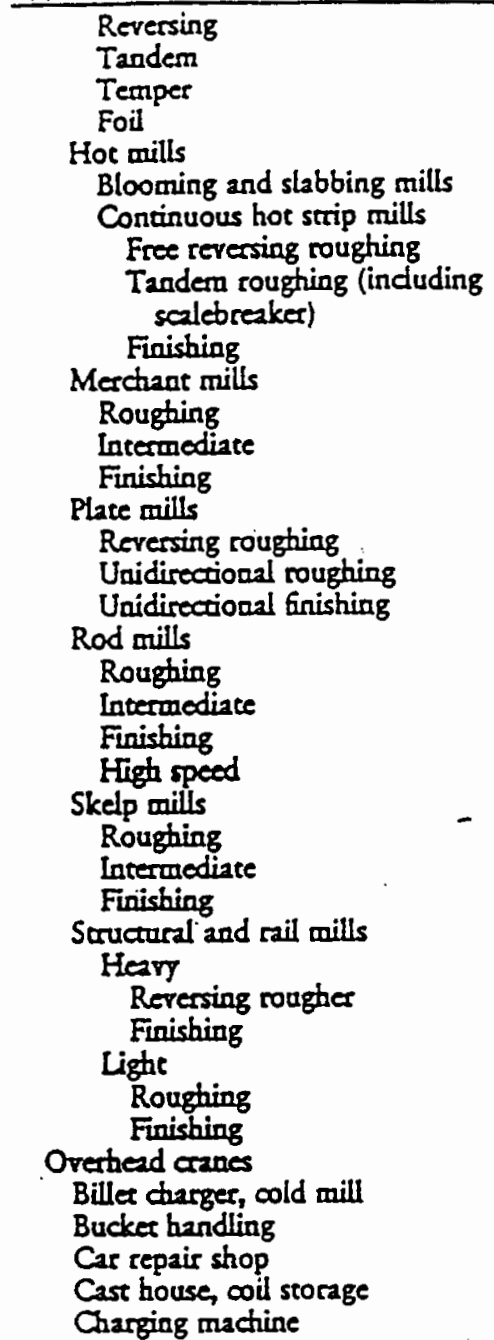 & $\begin{array}{l}5-6 \\
5-6 \\
5-6 \\
5-6 \\
6-7 \\
6-7 \\
7-8 \\
7-9\end{array}$ & 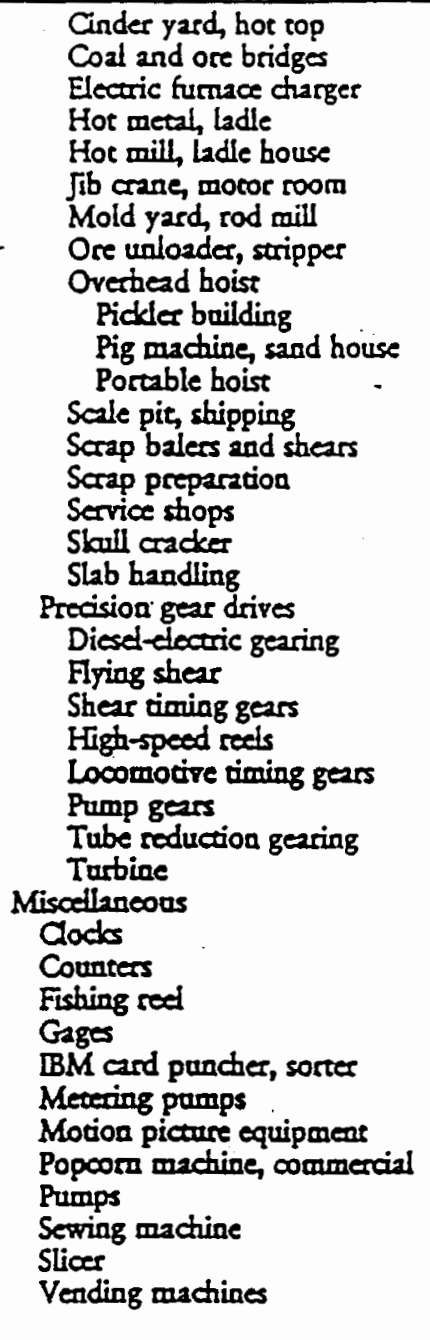 & $\begin{array}{c}8-9 \\
2-10 \\
9-10 \\
8-9 \\
9-10 \\
8-9 \\
8-9 \\
9-10 \\
6 \\
7-9 \\
6 \\
8-10 \\
8 \\
7-8 \\
8 \\
6-7 \\
5-7 \\
8 \\
7-8 \\
6-7\end{array}$ \\
\hline
\end{tabular}

Source: [AGMA 390.03, 23] 
TABIE VIII

MINIMUM NUMBER OF TEETH REQUIRED ON PINION FOR DIFFERENT HELIX AND PRESSURE ANGLES

Nore: Addendum 1//2d; whole depth $2.25 / l^{\prime 2}$.

\begin{tabular}{|c|c|c|c|c|}
\hline \multirow{2}{*}{ Ifclix angle, dog } & \multicolumn{4}{|c|}{$\frac{\text { Min. No. of teech to a void undercut }}{\text { Normal pressure angle } \phi_{m}}$} \\
\hline & 1435 & 20 & 2216 & 25 \\
\hline $\begin{array}{l}0 \text { (spur gears) } \\
5 \\
10 \\
15 \\
20 \\
23 \\
25 \\
30 \\
35 \\
40 \\
45\end{array}$ & $\begin{array}{l}32 \\
32 \\
31 \\
29 \\
27 \\
25 \\
24 \\
21 \\
18 \\
15 \\
12\end{array}$ & $\begin{array}{l}17 \\
17 \\
17 \\
16 \\
15 \\
14 \\
13 \\
12 \\
10 \\
8 \\
7\end{array}$ & $\begin{array}{l}14 \\
14 \\
14 \\
13 \\
12 \\
11 \\
11 \\
10 \\
8 \\
7 \\
5\end{array}$ & $\begin{array}{r}12 \\
12 \\
12 \\
11 \\
10 \\
10 \\
9 \\
8 \\
7 \\
6 \\
5\end{array}$ \\
\hline
\end{tabular}

Source: [Dudley, 7]

\section{TABLE IX}

RECOMMENDED HARDNESS VALUES FOR STEEL GEARS FOR DIFFERENT RANGES OF NUMBER OF PINION TEETH

\begin{tabular}{|c|c|c|c|}
\hline $\begin{array}{l}\text { Range of No. of } \\
\text { pinion teeth }\end{array}$ & $\begin{array}{l}\text { IRatio } \\
\text { ma }\end{array}$ & $\begin{array}{c}\text { Diametral } \\
\text { piteh } P_{d}\end{array}$ & Hardness \\
\hline $\begin{array}{l}19-60 \\
19-50 \\
19-45\end{array}$ & $\begin{array}{l}1-1.9 \\
2-3.9 \\
4-8\end{array}$ & $1-19,9$ & $200-240 \mathrm{BHN}$ \\
\hline $\begin{array}{l}19-45 \\
19-38 \\
19-35\end{array}$ & $\begin{array}{l}1-1.9 \\
2-3.9 \\
4-8\end{array}$ & $1-19.9$ & Ilockwell C 33-38 \\
\hline $\begin{array}{l}19-30 \\
17-26 \\
15-24\end{array}$ & $\begin{array}{l}1-1.9 \\
2-3.9 \\
4-8\end{array}$ & $1-19.9$ & llockwell C 58-63 \\
\hline
\end{tabular}

Source: [Dudley, 7] 


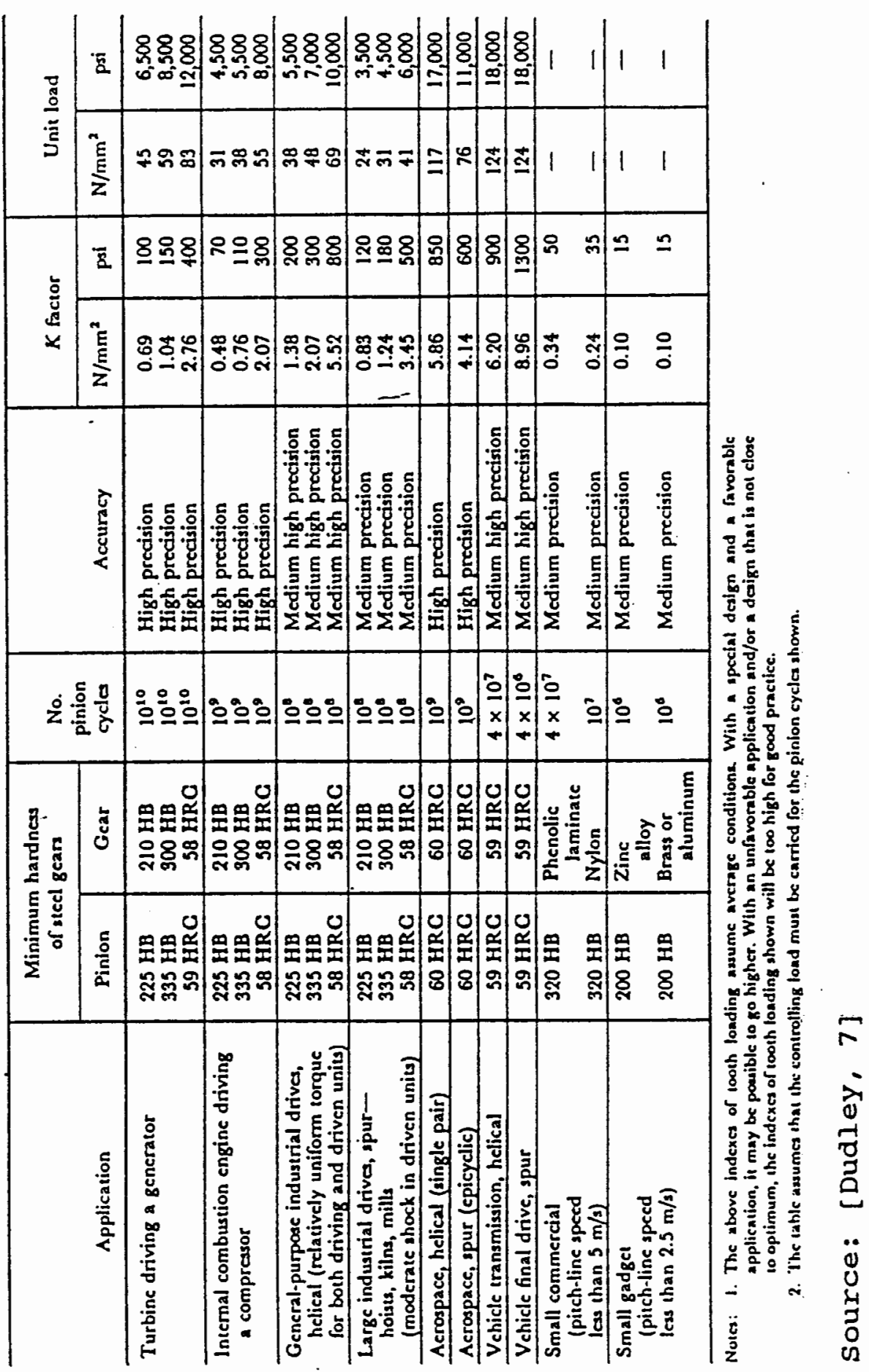




\section{ALLOWABIE CONTACT STRESS VALUES FOR}

DIFFERENT STEEL GEARS

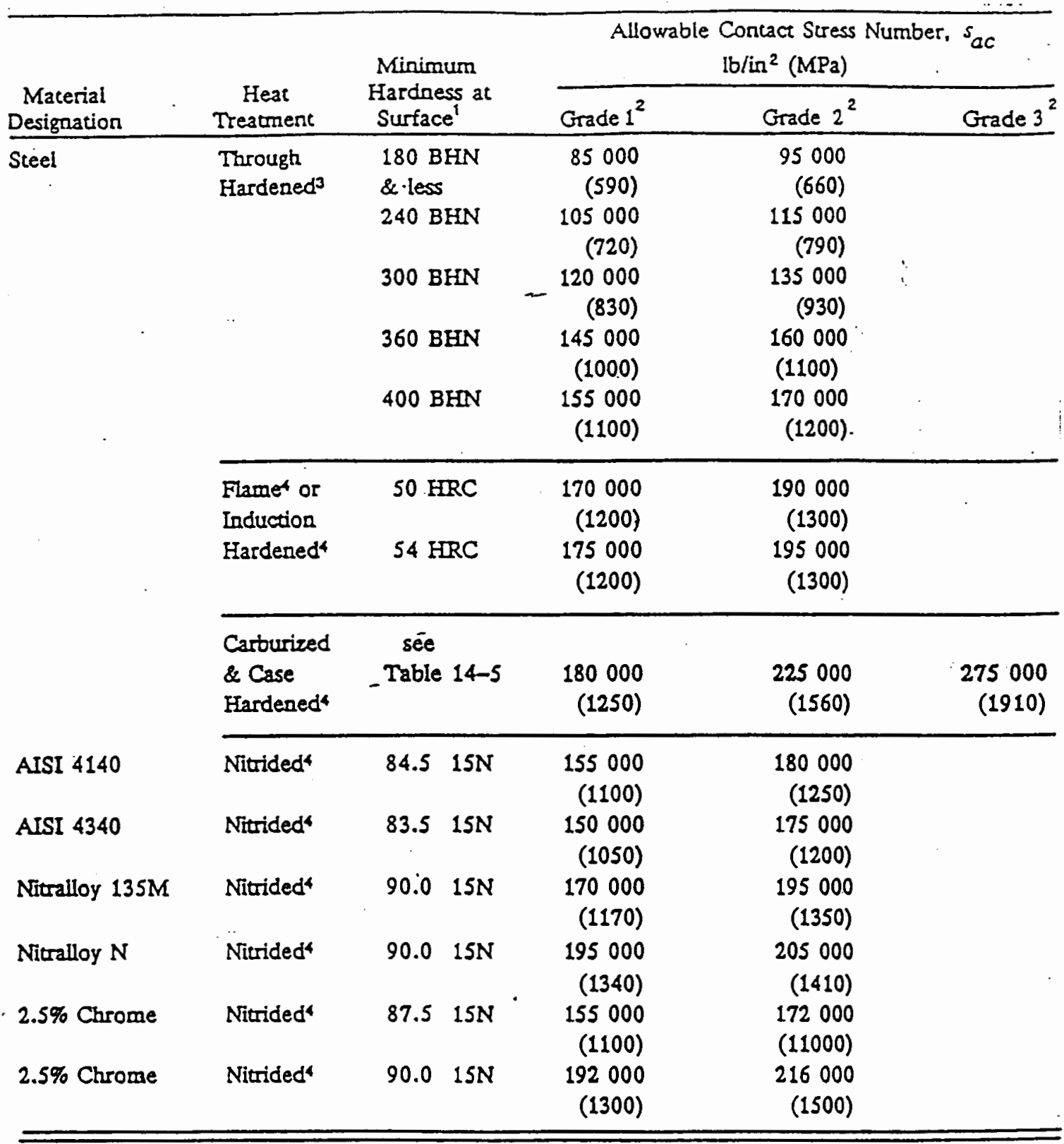

Source: [AGMA 2001-B88, 21] 


\section{TABLE XII}

\section{ALLOWABLE BENDING STRESS VALUES FOR} DIFFERENT STEEL GEARS

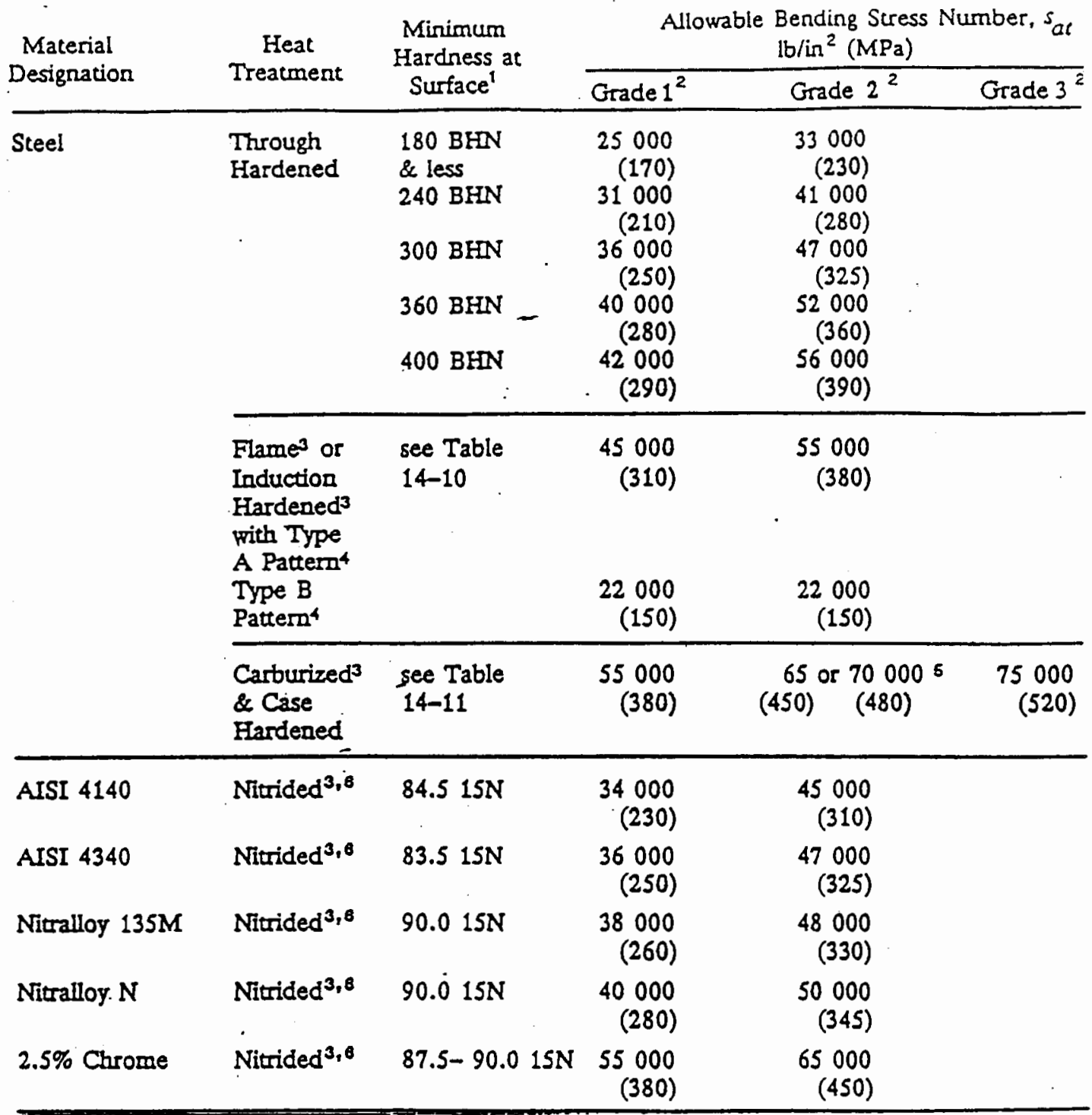

Source: [AGMA 2001-B88, 21] 


\section{APPLICATION FACTORS $K_{a}$ AND $C_{a}$ FOR VARIOUS APPLICATIONS}

\begin{tabular}{|c|c|c|c|}
\hline \multicolumn{3}{|c|}{ Prime mover } & \multirow[b]{2}{*}{ Driven equipment } \\
\hline Turbiac & Motot & $\begin{array}{l}\text { Iaternal } \\
\text { comburion } \\
\text { eagine }\end{array}$ & \\
\hline $\begin{array}{l}1.1 \\
1.3\end{array}$ & $\begin{array}{l}1.1 \\
1.3\end{array}$ & 1.3 & $\begin{array}{l}\text { Generztors and exciters } \\
\text { Base load or continuous } \\
\text { Peak duty cyde }\end{array}$ \\
\hline $\begin{array}{l}1.7 \\
1.7 \\
1.8 \\
2.2\end{array}$ & $\begin{array}{l}1.5 \\
1.5 \\
1.7 \\
2.0 \\
\end{array}$ & $\begin{array}{l}1.8 \\
1.8 \\
2.0 \\
2.5\end{array}$ & $\begin{array}{l}\text { Compreseors } \\
\text { Centrifugal } \\
\text { Acial } \\
\text { Rocary lobe (radial, wial, werew, and so forh) } \\
\text { Rociprocaning }\end{array}$ \\
\hline $\begin{array}{l}1.5 \\
2.0 \\
2.0 \\
1.7 \\
1.5 \\
2.0\end{array}$ & $\begin{array}{l}1.3 \\
1.7 \\
1.7 \\
1.5 \\
1.5 \\
2.0\end{array}$ & $\begin{array}{l}1.7 \\
- \\
2.0 \\
1.8 \\
2.3\end{array}$ & 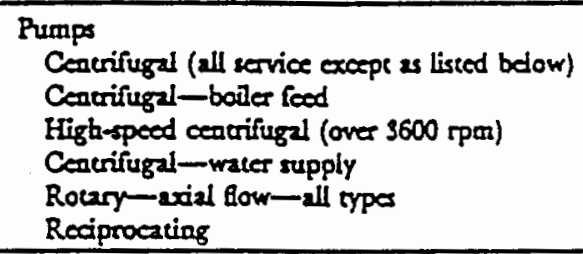 \\
\hline $1.7^{\circ}$ & 1.5 & 1.8 & $\begin{array}{l}\text { Blowers } \\
\text { Concrifugal }\end{array}$ \\
\hline $\begin{array}{l}1.7 \\
1.7 \\
2.0 \\
\end{array}$ & $\begin{array}{l}1.4 \\
1.4 \\
1.7 \\
\end{array}$ & $\begin{array}{l}1.8 \\
1.8 \\
2.2 \\
\end{array}$ & $\begin{array}{l}\text { Fans } \\
\text { Centrifugal } \\
\text { Forced draft } \\
\text { Induced draft } \\
\end{array}$ \\
\hline $\begin{array}{l}1.5 \\
1.3 \\
- \\
\end{array}$ & $\begin{array}{l}1.5 \\
1.3 \\
1.5 \\
\end{array}$ & $\bar{z}$ & $\begin{array}{l}\text { Paper indwery } \\
\text { Jordan or sefiaer } \\
\text { Paper machine, liae shafi } \\
\text { Pulp beacer }\end{array}$ \\
\hline $\begin{array}{l}1.5 \\
1.7 \\
1.7\end{array}$ & $\begin{array}{l}1.5 \\
1.5 \\
1.7\end{array}$ & $\begin{array}{l}1.8 \\
2.0 \\
2.0\end{array}$ & $\begin{array}{l}\text { Sugar indurtsy } \\
\text { Cane knife } \\
\text { Cencrifugal } \\
\text { Mill }\end{array}$ \\
\hline $\bar{z}$ & $\begin{array}{l}1.75 \\
1.75 \\
1.75 \\
\end{array}$ & $\bar{z}$ & $\begin{array}{l}\text { Processing mills } \\
\text { Autogenous, ball } \\
\text { Pulverizers } \\
\text { Cement mills } \\
\end{array}$ \\
\hline $\bar{z}$ & $\begin{array}{l}1.4 \\
2.0 \\
2.75\end{array}$ & $\bar{z}$ & $\begin{array}{l}\text { Metal rolling or drawing } \\
\text { Rod mills } \\
\text { Plzce mills, roughing } \\
\text { Hoc blooming or slabbing }\end{array}$ \\
\hline
\end{tabular}

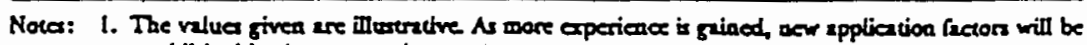
canblished in the goar trade

2. The values given may vay la a multisuge drive. Experience and rexdy will often show that the firse seage neods a different application fuctor thes that aceded for the lese seafe.

3. The power rating and the biod of gear arrangement affect the appliacioa factor. The vilues giver here represeal somewhel averge sicuscions. (Be wary of uex gear derigns of high

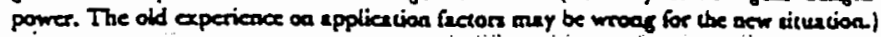

